\title{
Synthesis, characterization, molecular docking, analgesic, antiplatelet and anticoagulant effects of dibenzylidene ketone derivatives
}

\author{
Tauqeer Ahmed ${ }^{1}$, Arif-ullah Khan ${ }^{1 *}$, Muzaffar Abbass ${ }^{1,5}$, Edson Rodrigues Filho ${ }^{2}$, Zia Ud Din ${ }^{2,3}$ and Aslam Khan ${ }^{4}$
}

\begin{abstract}
In this study dibenzylidene ketone derivatives (2E,5E)-2-(4-methoxybenzylidene)-5-(4-nitrobenzylidene) cyclopentanone (AK-1a) and (1E,4E)-4-(4-nitrobenzylidene)-1-(4-nitrophenyl) oct-1-en-3-one (AK-2a) were newly synthesized, inspired from curcuminoids natural origin. Novel scheme was used for synthesis of AK-1a and AK-2a. The synthesized compounds were characterized by spectroscopic techniques. AK-1a and AK-2a showed high computational affinities (E-value $>-9.0 \mathrm{kcal} / \mathrm{mol}$ ) against cyclooxygenase-1, cyclooxygenase-2, proteinase-activated receptor 1 and vitamin K epoxide reductase. AK-1a and AK-2a showed moderate docking affinities (E-value $>-8.0 \mathrm{kcal} / \mathrm{mol}$ ) against mu receptor, kappa receptor, delta receptor, human capsaicin receptor, glycoprotein $\mathrm{Ilb} / \mathrm{llla}$, prostacyclin receptor $\mathrm{I}_{2}$ antithrombin-III, factor-II and factor-X. AK-1a and AK-2a showed lower affinities (E-value $>-7.0 \mathrm{kcal} / \mathrm{mol}$ ) against purinoceptor-3, glycoprotein-VI and purinergic receptor $\mathrm{P}_{2} \mathrm{Y}_{12}$. In analgesic activity, AK-1a and AK-2a decreased numbers of acetic acid-induced writhes ( $P<0.001$ vs. saline group) in mice. AK-1a and AK-2a significantly prolonged the latency time of mice ( $P<0.05, P<0.01$ and $P<0.001$ vs. saline group) in hotplate assay. AK-1a and AK-2a inhibited arachidonic acid and adenosine diphosphate induced platelet aggregation with $I_{50}$ values of $65.2,37.7,750.4$ and $422 \mu \mathrm{M}$ respectively. At 30, 100, 300 and $1000 \mu \mathrm{M}$ concentrations, AK-1a and AK-2a increased plasma recalcification time $(P<0.001$ and $P<0.001$ vs. saline group) respectively. At 100, 300 and $1000 \mu \mathrm{g} / \mathrm{kg}$ doses, AK-1a and AK-2a effectively prolonged bleeding time ( $P<0.001$ and $P<0.01$ vs. saline group) respectively. Thus in-silico, in-vitro and in-vivo investigation of AK-1a and AK-2a reports their analgesic, antiplatelet and anticoagulant actions.
\end{abstract}

Keywords: Dibenzylidene ketone derivatives, Computational studies, Analgesic, Antiplatelet, Anticoagulant, Arachidonic acid

\section{Introduction}

Pain is an unfavorable sensory and emotional experience that is associated with the potential tissue damage and explained in terms of such damage [1]. Noxious effects such as ulceration, gastrointestinal bleeding by non-steroidal anti-inflammatory drugs and drowsiness, nausea and tolerance by opiates usage limits their use in management of pain [2]. Platelets play vital role in a complex

\footnotetext{
*Correspondence: arif.ullah@riphah.edu.pk

${ }^{1}$ Riphah Institute of Pharmaceutical Sciences, Riphah International University, Islamabad, Pakistan

Full list of author information is available at the end of the article
}

processes which are involved in haemostasis and thrombosis [3]. The most common cause of peripheral artery diseases (PAD) is atherosclerosis and such patients have more chance of myocardial infarction, stroke or death with cardiovascular events and it is 3:1 in comparison to persons without PAD [4]. Antiplatelet agents are used in management of arterial thrombosis. Moreover, anticoagulants inhibit proteases in coagulation cascade [5]. Interference in natural balance among pro-coagulant and anticoagulant due to genetic or any other acquired factors may results in bleeding or thrombotic disorders. Thrombin is a key enzyme of coagulation cascade which has many significant biological functions including platelet 
activation, fibrinogen conversion to fibrin network and feedback amplification of coagulation. Different tissue factors are involved in thrombus formation in order to prevent heamorrhage [6]. Coagulation cascade involves intrinsic and extrinsic pathways [7]. The former has a role in the growth and maintenance of fibrin while the later plays its role in the initiation of fibrin formation. Extrinsic pathway requires tissue factors for its activation which after vascular injury becomes exposed to the blood which ultimately results in thrombin activation [8]. Among antiplatelet agent and anticoagulant drugs which are available commercially, for thrombotic disorders, these agents are associated with certain limitations and side effects [9]. Chemically curcumin is 1,7-bis (4-hydroxy3-methoxyphenyl)-1,6-heptadiene-3,5-dione. It is a yellow-orange colored pigment which is derived from the rhizome of Curcuma longa [10]. The plant has a wide spectrum of pharmacological properties and traditionally it has been used for many ailments since centuries [11]. The reported activities of curcumin are antioxidant, anti-inflammatory, antitumor, antibacterial, antifungal and antiviral [10]. Curcumin also showed inhibition in platelet aggregation and antithrombotic effects $[12,13]$. Concerning structural aspects, dibenzylidene ketone moieties are considered curcumin analogues, which are compounds of great importance. Structurally, curcuminoids contains two aryl rings connected at the ends of a $\mathrm{C}_{7}$ carbon-chain where a dienone composes an extended conjugated system. Dibenzylidene ketone derivatives also contain a dienone system connecting two aryl groups at the ends of a $C_{5}$ carbon chain. Dienones are good Michel acceptors, allowing its reaction with important biomolecules interfering in biological processes. Previous reported activities of dibenzylidene ketone derivatives include antiparasitic activity, cytotoxicity, antimicrobial activity, analgesic activity [14-16]. Based on previous literature studies, two novel dibenzylidene ketone derivatives i.e. (2E,5E)-2-(4-methoxybenzylidene)-5-(4nitrobenzylidene) cyclopentanone (AK-1a) and (1E,4E)4-(4-nitrobenzylidene)-1-(4-nitrophenyl) oct-1-en-3-one (AK-2a) were synthesized and characterized. AK-1a and AK-2a were investigated for their analgesic, antiplatelet and anticoagulant effects using different pharmacological and computational assays.

\section{Materials and methods Chemicals}

Adenosine diphosphate (ADP) and arachidonic acid (AA) were purchased from Chrono-Log association. Benzaldehyde, cyclopentanone, dimethyl sulfoxide, ethanol and methoxybenzaldehyde were purchased from Merck Millipore., Billerica, MA, USA. Aspirin, calcium chloride $\left(\mathrm{CaCl}_{2}\right)$, diclofenac sodium, heparin, phosphate buffers solution (PBS) and sodium citrate were obtained from Sigma chemicals., Dt. Louis, MO, USA. The tramadol was acquired from Searle Karachi-Pakistan. All chemicals used were of analytical grade.

\section{Animals}

Balb-C mice (25-30 g) of both gender were utilized for this study. All animals were housed according to the standard protocols $25 \pm 2{ }^{\circ} \mathrm{C}, 12 \mathrm{~h}$ duration of natural light and dark cycle. Healthy diet was given to mice and water ad libitum. The study was performed in accordance with protocols of Institute of Laboratory Animal Resources, Commission on Life Sciences University, National Research Council (1996) and approved by Riphah Institute of Pharmaceutical Sciences (RIPS) Ethical Committee (Reference No: REC/RIPS/2016/009).

\section{Synthesis of AK-1a and AK-2a}

Novel way of synthesis was carried out. The monoarylidene derivative was synthesized by the reaction of cyclopentanone with $p$-methoxy benzaldehyde. DIMCARB was utilized as a catalyst in this reaction. DIMCARB was used in catalytic amount to obtain selective monoarylidene cyclic derivative in a green solvent (EtOH: $\mathrm{H}_{2} \mathrm{O}$ ), further second step leads to get an unsymmetrical bis-(arylmethylidene)-cycloalkanones. The synthesis of compound was carried out at room temperature from the reaction of intermediate 1 with $p$-nitro benzaldehyde. The scheme of the synthesized compound along with its structure is shown in Fig. 1. Chemical characterization was carried out based on the analysis of spectroscopic data. Fourier transform mass spectrometry (FTMS) of AK-1a as shown in Fig. 2. Synthesis of AK-2a was carried in a two-step reaction. In the first step, cycloalkanone was reacted with an aldehyde in a DIMCARB catalysed reaction, while in the second step monoarylidene derivative was reacted with the aldehyde through knoevenagel condensation to get the required product. DIMCARB can be recovered by distillative dissociation-reassociation process in a vacuum or under an atmosphere of $\mathrm{CO}_{2}$. The 2-heptanone was reacted with $p$-nitro benzaldehyde in an acidic medium to get intermediate, and then intermediate yield AK-2a. The scheme of the novel synthesized compound AK-2a along with its structure is shown in Fig. 1. Chemical characterization was carried out based on the analysis of spectroscopic data. Fourier transform mass spectrometry (FTMS) of AK-2a as shown in Fig. 3.

\section{Spectral analysis \\ AK-1a}

Percent yield: 84. Decompose at: $96-98{ }^{\circ} \mathrm{C} .{ }^{1} \mathrm{H}$ NMR $\left(400 \mathrm{MHz}, \mathrm{CDCl}_{3}\right) \delta 7.57(\mathrm{~d}, \mathrm{~J}=8.8 \mathrm{~Hz}, 3 \mathrm{H}), 7.52(\mathrm{~d}$, 

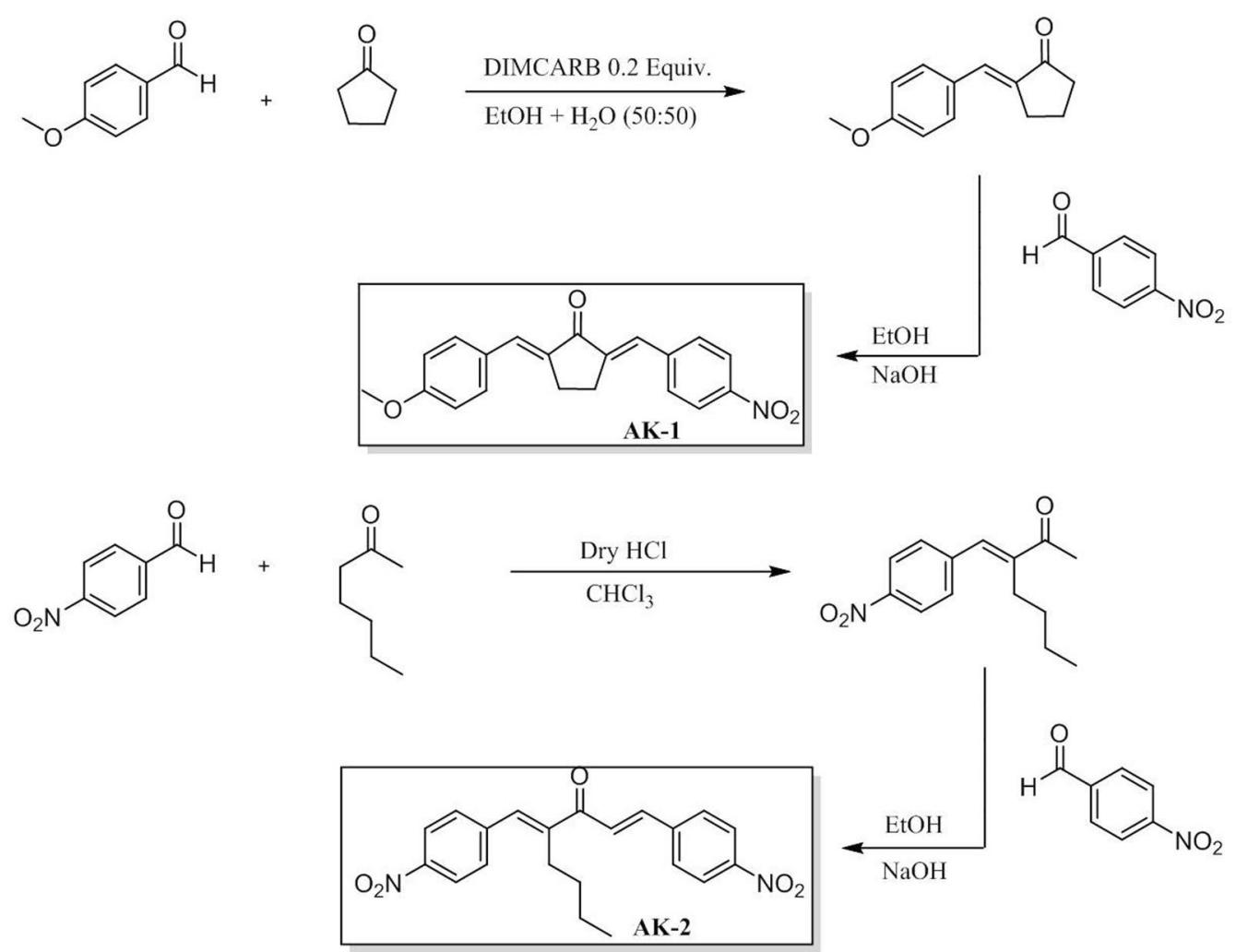

Fig. 1 Chemical structure and synthesis of (2E,5E)-2-(4-methoxybenzylidene)-5-(4-nitrobenzylidene) cyclopentanone (AK-1a) and (1E,4E)-4-(4-nitrob enzylidene)-1-(4-nitrophenyl)oct-1-en-3-one (AK-2a)

$\mathrm{J}=8.4 \mathrm{~Hz}, 3 \mathrm{H}), 7.40(\mathrm{~d}, \mathrm{~J}=8.6 \mathrm{~Hz}, 2 \mathrm{H}), 6.97(\mathrm{~d}, \mathrm{~J}=8.9 \mathrm{~Hz}$, 2H), 3.86 (s, 3H), 3.08 (s, 4H). ${ }^{13} \mathrm{C}$ NMR (101 MHz, $\left.\mathrm{CDCl}_{3}\right) \delta 196.21$ (1C), 160.90 (1C), 138.27 (1C), 135.28 (1C), 134.71 (1C), 134.32 (1C), 132.73 (2C), 131.93 (2C), 129.16 (2C), 128.70 (1C), 114.51 (2C), 77.48 (1C), 76.84 (1C), 55.54 (1C), 26.60 (2C). HRMS ESI(+): calcd for $\mathrm{C}_{20} \mathrm{H}_{17} \mathrm{NNaO}_{4}{ }^{+}(\mathrm{M}+\mathrm{Na})$ 358.1050, found 358.1044.

\section{AK-2a}

Percent yield: 80. m.p: $180.5-181.5{ }^{\circ} \mathrm{C} .{ }^{1} \mathrm{H}$ NMR $\left(400 \mathrm{MHz}, \mathrm{CDCl}_{3}\right) \delta 8.28(\mathrm{dd}, \mathrm{J}=8.5,7.7 \mathrm{~Hz}, 4 \mathrm{H}), 7.80-$ $7.70(\mathrm{~m}, 3 \mathrm{H}), 7.56(\mathrm{~d}, \mathrm{~J}=8.7 \mathrm{~Hz}, 2 \mathrm{H}), 7.49(\mathrm{~s}, 1 \mathrm{H}), 7.43$ $(\mathrm{d}, \mathrm{J}=15.7 \mathrm{~Hz}, 1 \mathrm{H}), 2.65-2.58(\mathrm{~m}, 2 \mathrm{H}), 1.53-1.42(\mathrm{~m}$, $2 \mathrm{H}), 1.37(\mathrm{dd}, \mathrm{J}=14.7,7.2 \mathrm{~Hz}, 2 \mathrm{H}), 0.91(\mathrm{t}, \mathrm{J}=7.2 \mathrm{~Hz}$, 3H). ${ }^{13} \mathrm{C}$ NMR $\left(101 \mathrm{MHz}, \mathrm{CDCl}_{3}\right) \delta 191.74$ (1C), 148.73 (1C), 147.58 (1C), 146.65 (1C), 142.33 (1C), 141.43 (1C), 141.07 (1C), 135.88 (1C), 129.97 (2C), 129.03 (2C), 125.92 (1C), 124.38 (2C), 124.01 (2C), 31.22 (1C), 27.24 (1C), 23.03 (1C), 13.94 (1C). HRMS ESI(+): calcd for $\mathrm{C}_{21} \mathrm{H}_{20} \mathrm{~N}_{2}$ $\mathrm{NaO}_{5}{ }^{+}(\mathrm{M}+\mathrm{Na})$ 403.1264, found 403.1240.

\section{In-silico study}

Molecular docking is an informative tool which is used to investigate the affinity between ligand and protein targets. We used Auto Dock Vina program for docking study through PyRx $[17,18]$. Affinity of best docked pose of ligand and protein target complex was determined by E-value $(\mathrm{kcal} / \mathrm{mol})$. It provides prediction of binding free energy and binding constant for docked ligands [19]. 3D-structures of test compounds (AK-1a and $\mathrm{AK}-2 \mathrm{a}$ ) were prepared in discovery studio visualiser (DSV) and saved as PDB format. 3D-structures of target proteins were taken from http://www.rcsb.org/ $\mathrm{pdb} /$ home/home.do. The target proteins involved in pain pathways are cyclooxygenase-1 (COX-1, PDB-ID: 3N8X), cyclooxygenase-2 (COX-2, PDB-ID: 1PXX), mu receptor (PDB-ID: 5C1M), kappa receptor (PDB-ID: 4DJH), delta receptor (PDB-ID: 4EJH), human capsaicin receptor (HCR, PDB-ID: 3J9J) and purinoceptor-3 (P2X3, PDB-ID: 5SVL). The target proteins involved in platelet aggregation are glycoprotein-IIb/IIIa (GP-IIb/ IIIa, PDB-ID: 2VDM), glycoprotein-VI (GP-VI, PDB-ID: 2G17), purinergic receptor $\left(\mathrm{P}_{2} \mathrm{Y}_{12}\right.$, PDB-ID: 4PXZ), prostacyclin receptor $\mathrm{I}_{2}$ (PG-I $\mathrm{I}_{2}$, PDB-ID: 4F8K) and proteinase-activated receptor 1 (PAR-1, PDB-ID: 3VW7). The target proteins involved in blood coagulation process are antithrombin-III (AT-III, PDB-ID: 2B4X), factor-II (F-II, PDB-ID: 1KSN), factor-IX (F-IX, PDB-ID: 1XMN), 


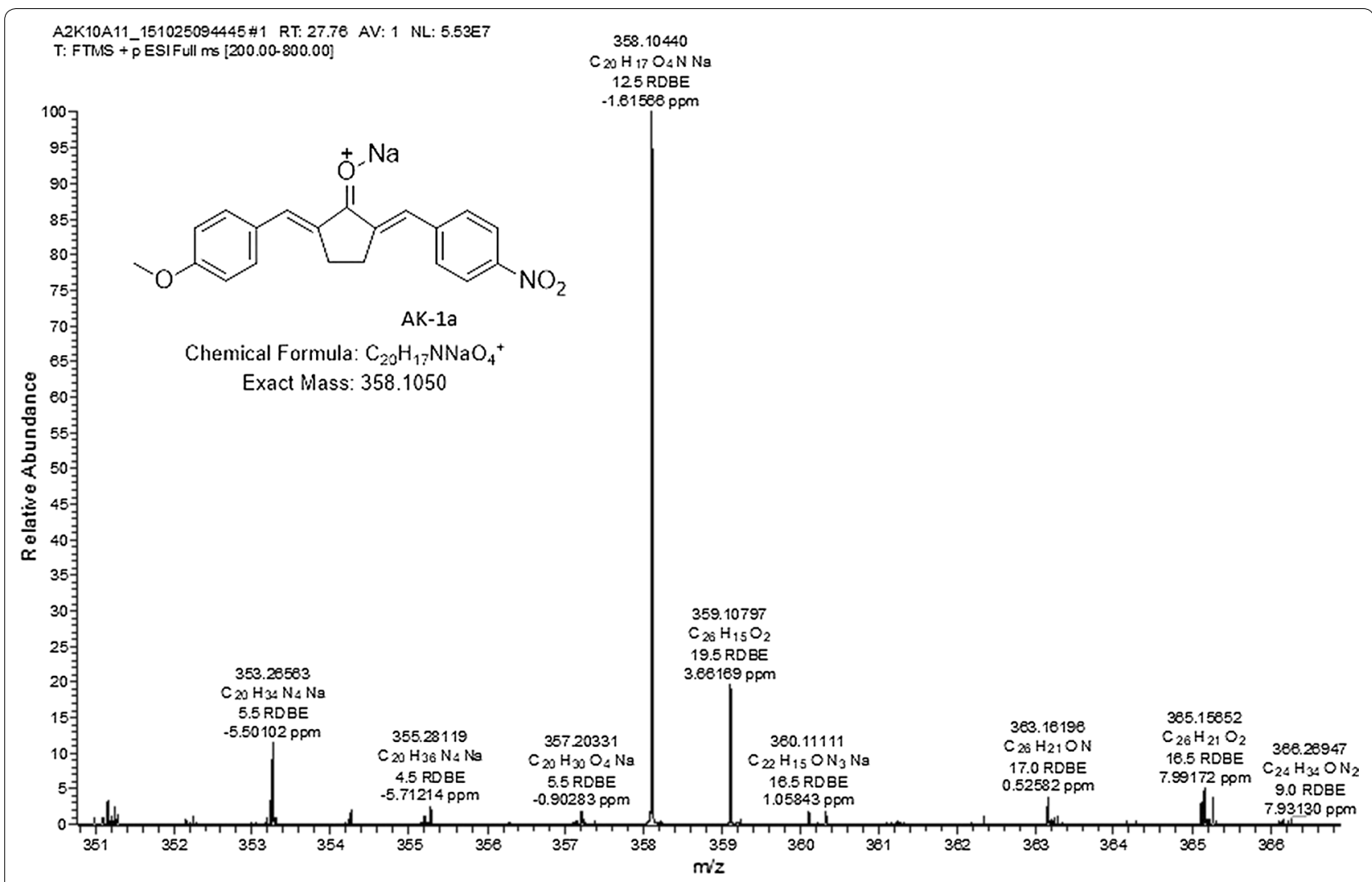

Fig. 2 Represents Fourier transform mass spectrometry (FTMS) of (2E,5E)-2-(4-methoxybenzylidene)-5-(4-nitrobenzylidene) cyclopentanone (AK-1a)

factor-X (F-X, PDB-ID: 1RFN) and vitamin-K epoxide reductase (VKOR, PDB-ID: 3KP9). All the target proteins were then purified by removing ligands and other entities which might occupy nearby space using Biovia Discovery Studio Client 2016. The structures of standard drug molecules were downloaded from pubchem data base (https ://pubchem.ncbi.nlm.nih.gov/search/). Reference analgesic drugs are aspirin (PubChem CID: 2244), morphine (PubChem CID: 5288826) and capsazepine (PubChem CID: 2733484). Standard antiplatelet drugs are aspirin (PubChem CID: 2244), tirofiban (PubChem CID: 60947), hinokitiol (PubChem CID: 3611), clopidogrel (PubChem CID: 10066813), beraprost (PubChem CID: 6917951) and vorapaxar (PubChem CID: 10077130). Reference anticoagulant drugs are heparin sulphate (PubChem CID: 53477714), apixaban (PubChem CID: 10182969), argatroban (PubChem CID: 92722), pegnivacogin (PubChem CID: 86278323) and warfarin (PubChem CID: 54678486). All these structures were downloaded in .xml format and converted to PDB format via Open Babel JUI software. PDB form of both ligand and standard as well as target proteins were converted to PDBQT via AutoDockTools (Version1.5.6 Sep_17_14) where add kollman charges and compute gastegier charges were added and Ad4 type was assigned. Both the test compounds along with protein targets in PDBQT form were loaded in software named as PyRx and then docked against the respective targets. Binding affinity was calculated and shown in $\mathrm{kcal} / \mathrm{mol}$. For post docking interaction Discovery studio visualizer was used for number of hydrogen bonds (classical and non-classical) and binding amino acid residues: alanine (ALA), asparagine (ASN), arginine (ARG), aspartic acid (ASP), cysteine (CYS), glutamine (GLN), glutamic acid (GLU), glycine (GLY), histidine (HIS), leucine (LEU), lysine (LYS), serine (SER), threonine (THR), tryptophan (TRP), tyrosine (TYR), valine (VAL) and phenylalanine (PHE) showed in the form 2D interaction.

\section{Analgesic models}

The analgesic activity was carried out by using two standard protocols i.e. acetic acid-induced writhing test and hot plate test in order to evaluate the peripheral and central effects of analgesia.

\section{Acetic acid-induced writhing test}

Mice were divided into five different groups, having five mice in each. After 30 min writhing were induced by an IP injection of $0.1 \mathrm{~mL}$ of $0.7 \%$ (by volume) acetic acid 
A11K11A11 35 RT: 1,04 AV: 1 SB: 11 0,91-1,16 NL: 2,73ES

T: FTMS + p ESI Full ms $[150,00-950,00]$

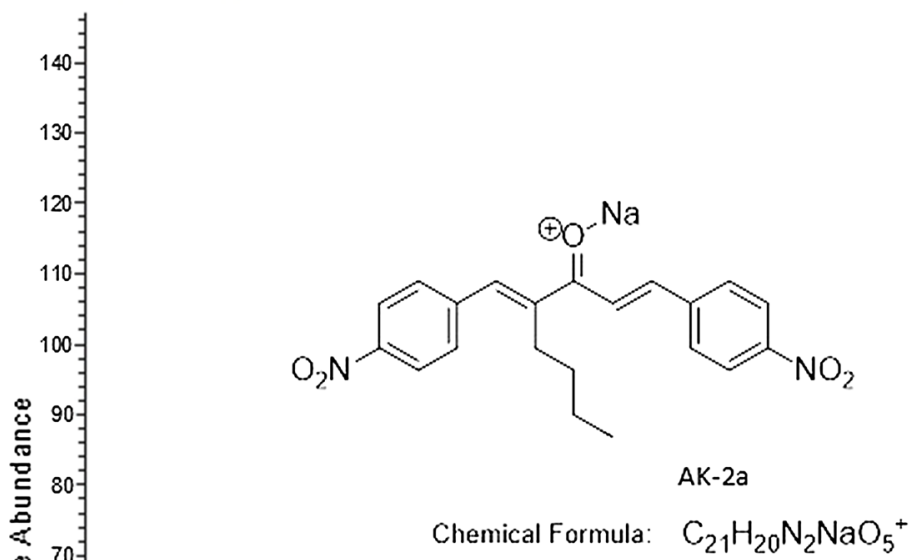

Exact Mass: 403,1264

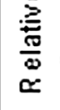

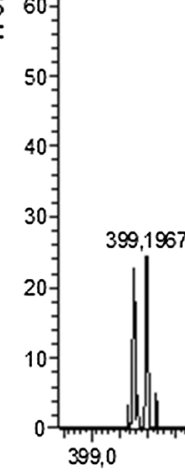

Fig. 3 Represents Fourier transform mass spectrometry (FTMS) of (1E,4E)-4-(4-

$\mathrm{m}^{\prime} \mathbf{z}$

solution [20]. Drug pretreatment times were chosen so that writhing was counted over a period of maximum analgesic activity. AK-1a and AK-2a in a dose-dependent manner $(0.5-100 \mathrm{mg} / \mathrm{kg})$ decreased acetic acidinduced writhes injected through intraperitoneal (IP) route. Perception of pain was recorded in the form of abdominal constrictions and stretches of the hind limb called as a writhe. Some mice showed half writhe. Two half writhes were considered as equal to one full writhe. The writhing episodes were recorded for $20 \mathrm{~min}$. Control group was administered with normal saline $(10 \mathrm{~mL} /$ $\mathrm{kg}$ ). Diclofenac sodium was used as a positive control.

\section{Hot plate test}

The latency period of the test compounds were evaluated by hot plate assay according to the protocols as previously used with little modifications [21]. Mice were divided into five different groups, having five mice in each. The animals were placed individually on the hot plate $\left(55 \pm 2{ }^{\circ} \mathrm{C}\right)$ and the observations (jumping or licking paws) were recorded at 30, 60, 90 and $120 \mathrm{~min}$. Normal saline $(10 \mathrm{~mL} / \mathrm{kg})$ was given to control group, tramadol (30 $\mathrm{mg} / \mathrm{kg}$ ) was used as a positive control.

\section{Antiplatelet assay}

Antiplatelet activity was performed to check whether the test compounds possess any effect on platelet aggregation. It was determined by whole-blood aggregometry method, which was performed by an impedance aggregometer (Model 591, Chrono-Log) as previously described [22]. Arterial or venous blood samples were collected from healthy volunteers in plastic tubes having $3.2 \%$ sodium citrate anticoagulant (9:1). Measurements were performed at $37{ }^{\circ} \mathrm{C}$ and $1200 \mathrm{rpm}$ stirring speed. According to the manufacturer recommendations, $0.5 \mathrm{~mL}$ of citrated blood was diluted with same volume of normal saline $(0.9 \%)$ which was prewarmed for $5 \mathrm{~min}$ at $37^{\circ} \mathrm{C} .30 \mu \mathrm{L}, \mathrm{AK}-1 \mathrm{a}$ and AK-2a at 1, 3, 10, 30, 100, 300, $1000 \mu \mathrm{M}$ concentrations were also added to the tube. After placing the electrode, aggregation was induced by 
different agonists like AA $(1.5 \mathrm{mM})$ and ADP $(10 \mu \mathrm{M})$. Platelet aggregation response was continually monitored for $6 \mathrm{~min}$ as an electrical impedance in ohms. Then mean percent platelet inhibition was calculated. Aspirin was used as positive control.

\section{Anticoagulant activity}

Anticoagulant activity of the test compounds were performed using following experiments.

\section{Plasma recalcification time (PRT)}

Anticoagulant potential of the test compounds were determined by PRT method [23]. The blood samples were obtained from healthy volunteers in tubes containing $3.8 \%$ sodium citrate $(9: 1)$ in order to prevent the clotting process. Centrifugation (15 $\mathrm{min}$ at rate $3000 \mathrm{rpm}$ ) was carried out in order to obtain platelet poor plasma. $0.2 \mathrm{~mL}$ plasma, $0.1 \mathrm{~mL}$ of different concentration of the test compounds (30,100, 300 and $1000 \mu \mathrm{M})$ and $0.3 \mathrm{~mL}$ of $\mathrm{CaCl}_{2}(25 \mathrm{mM})$ were then added together in a clean fusion tube and incubated in a water bath at $37{ }^{\circ} \mathrm{C}$. Heparin $(440 \mu \mathrm{M})$ was used as positive control. The clotting time was recorded with a stopwatch by tilting the test tubes every $5 \mathrm{~s}$.

\section{Bleeding time (BT)}

Anticoagulant potential of AK-1a and AK-2a was also determined by in-vivo tail BT method in mice [24]. AK- $1 \mathrm{a}$ and AK-2a (100, 300 and $1000 \mu \mathrm{g} / \mathrm{kg})$ were administered intravenously via tail vein of mice. After $10 \mathrm{~min}$ mice were anesthetized using diethyl ether and a sharp cut $(3 \mathrm{~mm})$ deep at tip of the tail were made. The tail was then immersed into PBS which was pre warmed to $37{ }^{\circ} \mathrm{C}$. BT was recorded from the time when bleeding started till it stopped completely observation was made up-to $10 \mathrm{~min}$. Heparin $(40 \mu \mathrm{g} / \mathrm{kg})$ was utilized as a positive control.

\section{Statistical analysis}

Data were expressed as mean \pm standard error of mean (SEM) and analyzed by using one-way analysis of variance (ANOVA), with post hoc Tukey's test. Data were considered significant at $P<0.05$. Bar graphs were analyzed using Graph Pad Prism (GraphPad, San Diego, CA, USA).

\section{Results}

\section{Molecular docking evaluation}

The results of E-values, hydrogen bonds and binding residues of AK-1a and AK-2a with target proteins involved in pain pathways along with standard drugs are shown in Table 1 and Figs. 4 5, 6, 7. The results of E-values, hydrogen bonds and binding residues of AK-1a and AK-2a with target proteins involved in platelet aggregation along with standard drugs are shown in Table 2 and Figs. 7, 8, 9. The results of E-values, hydrogen bonds and binding residues of AK-1a and AK-2a with target proteins involved in coagulation process along with the standard drugs are shown in Table 3 and Figs. 10, 11, 12.

\section{Effect on acetic acid-induced writhings}

Saline group $(10 \mathrm{~mL} / \mathrm{kg})$ showed $88 \pm 2.28$ numbers of writhes. The writhes count in AK-1a treated group (1, $10,20,30$ and $100 \mathrm{mg} / \mathrm{kg}$ ) were decreased to $77 \pm 1.51$, $60.60 \pm 1.07,51.80 \pm 0.73,42.40 \pm 1.72$ and $33.80 \pm 1.20$ $(P<0.001$ vs. saline group $)$ respectively. Diclofenac sodium $(20 \mathrm{mg} / \mathrm{kg})$ decreased numbers of writhes to $29.80 \pm 1.77$ ( $P<0.001$ vs. saline group). AK-2a showed significant response in acetic acid induced writhing. The writhes count in AK-2a treated group (0.5, 1, 3 and $5 \mathrm{mg} / \mathrm{kg}$ ) were decreased to $52.40 \pm 1.40,38.60 \pm 1.20$, $32.60 \pm 1.50$ and $2.00 \pm 1.26$ ( $P<0.001$ vs. saline group) respectively as shown in Fig. 13.

\section{Effect on latency time}

The latency time of saline group $(10 \mathrm{~mL} / \mathrm{kg})$ at 0 , $30,60,90$ and $120 \mathrm{~min}$ were $7.35 \pm 0.12,8.33 \pm 0.13$, $8.56 \pm 0.10,8.71 \pm 0.10$ and $8.70 \pm 0.03$ s respectively. AK-1a dose dependently (1, 10, 20 and $30 \mathrm{mg} / \mathrm{kg}$ ) prolonged latency time against thermal pain generation. The latency time of AK-1a $(1 \mathrm{mg} / \mathrm{kg})$ treated group at $0,30,60,90$ and $120 \mathrm{~min}$ were $5.42 \pm 0.15,6.28 \pm 0.15$, $8.63 \pm 0.28, \quad 10.40 \pm 0.19, \quad 11.47 \pm 0.27$ s $\quad(P<0.001$ vs. saline group) respectively. The latency time of AK-1a $(10 \mathrm{mg} / \mathrm{kg})$ treated group at $0,30,60,90,120 \mathrm{~min}$ were $5.78 \pm 0.28, \quad 7.51 \pm 0.20, \quad 9.36 \pm 0.32, \quad 10.71 \pm 0.39$ and $12.80 \pm 0.24 \mathrm{~s}(P<0.001$ vs. saline group) respectively. The latency time of AK-1a $(20 \mathrm{mg} / \mathrm{kg})$ treated group at $0,30,60,90$ and $120 \mathrm{~min}$ were $7.33 \pm 0.29,8.81 \pm 0.26$, $9.27 \pm 0.33,11.81 \pm 0.24$ and $16.92 \pm 0.55 \mathrm{~s}(P<0.001$ vs. saline group) respectively. The latency time of AK-1a $(30 \mathrm{mg} / \mathrm{kg})$ treated group at $0,30,60,90$ and $120 \mathrm{~min}$ were $9.69 \pm 0.31,10.40 \pm 0.36,11.88 \pm 0.13,13.67 \pm 0.23$ and $15.66 \pm 0.33 \mathrm{~s}(P<0.001$ vs. saline group $)$ respectively. The latency time of tramadol $(30 \mathrm{mg} / \mathrm{kg})$ treated group at $0,30,60,90$ and $120 \mathrm{~min}$ were $7.33 \pm 0.20$, $13.07 \pm 0.18,13.97 \pm 0.12,14.69 \pm 0.27$ and $15.61 \pm 0.18 \mathrm{~s}$ $(P<0.001$ vs. saline group) respectively as shown in Fig. 14. AK-2a dose dependently $(0.5,1,3$ and $5 \mathrm{mg} / \mathrm{kg}$ ) prolonged latency time against thermal pain generation. The latency time of AK-2a $(0.5 \mathrm{mg} / \mathrm{kg})$ treated group at $0,30,60,90$ and $120 \mathrm{~min}$ were $4.85 \pm 0.32,8.23 \pm 0.12$, $9.45 \pm 0.12 \mathrm{~s}(P<0.01$ vs. saline group $), 10.48 \pm 0.17$ and $11.32 \pm 0.12 \mathrm{~s}(P<0.001$ vs. saline group $)$ respectively. The latency time of AK-2a $(1 \mathrm{mg} / \mathrm{kg})$ treated group at $0,30,60,90$ and $120 \mathrm{~min}$ were $5.89 \pm 0.26,8.55 \pm 0.06$, 


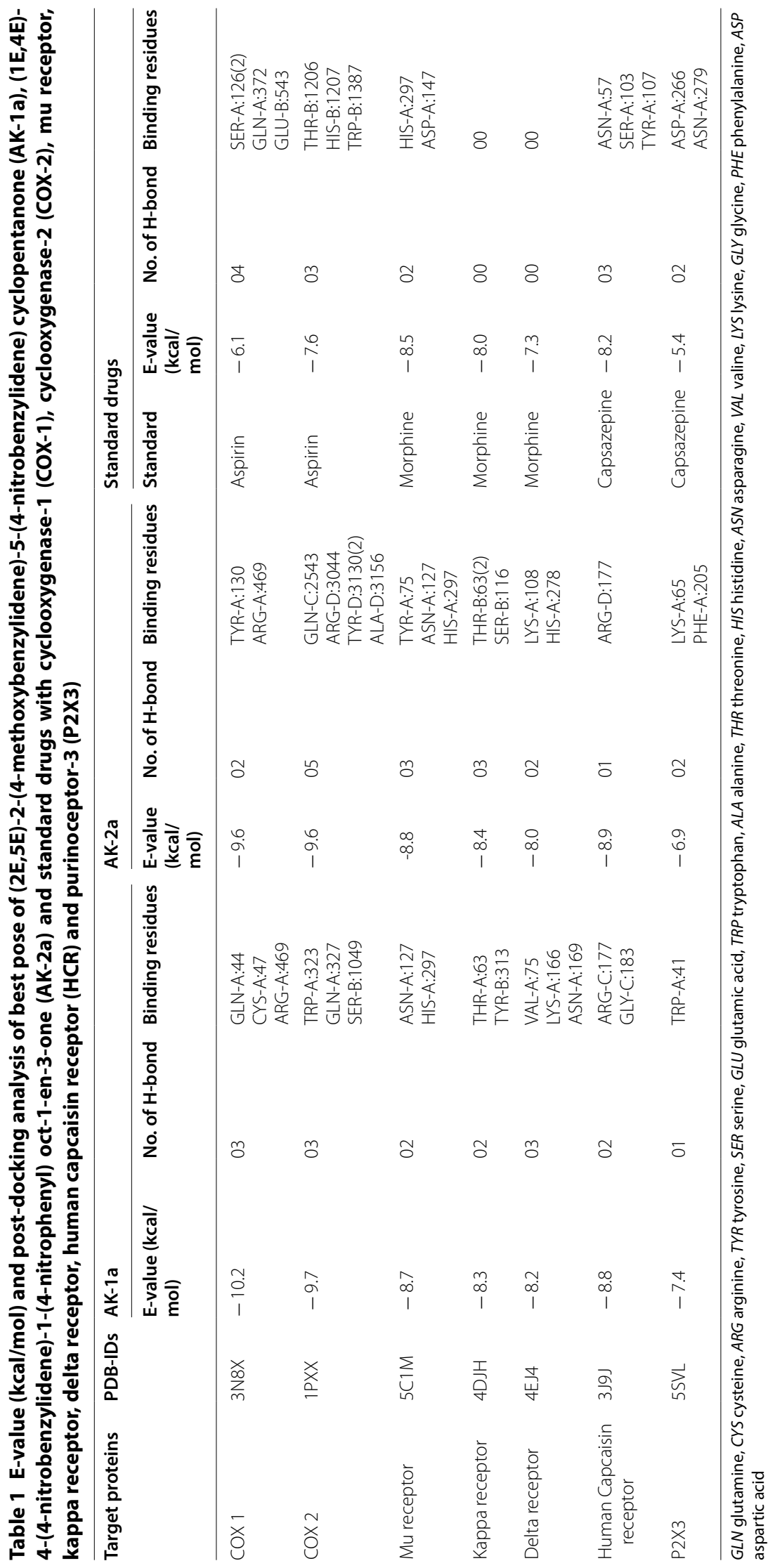




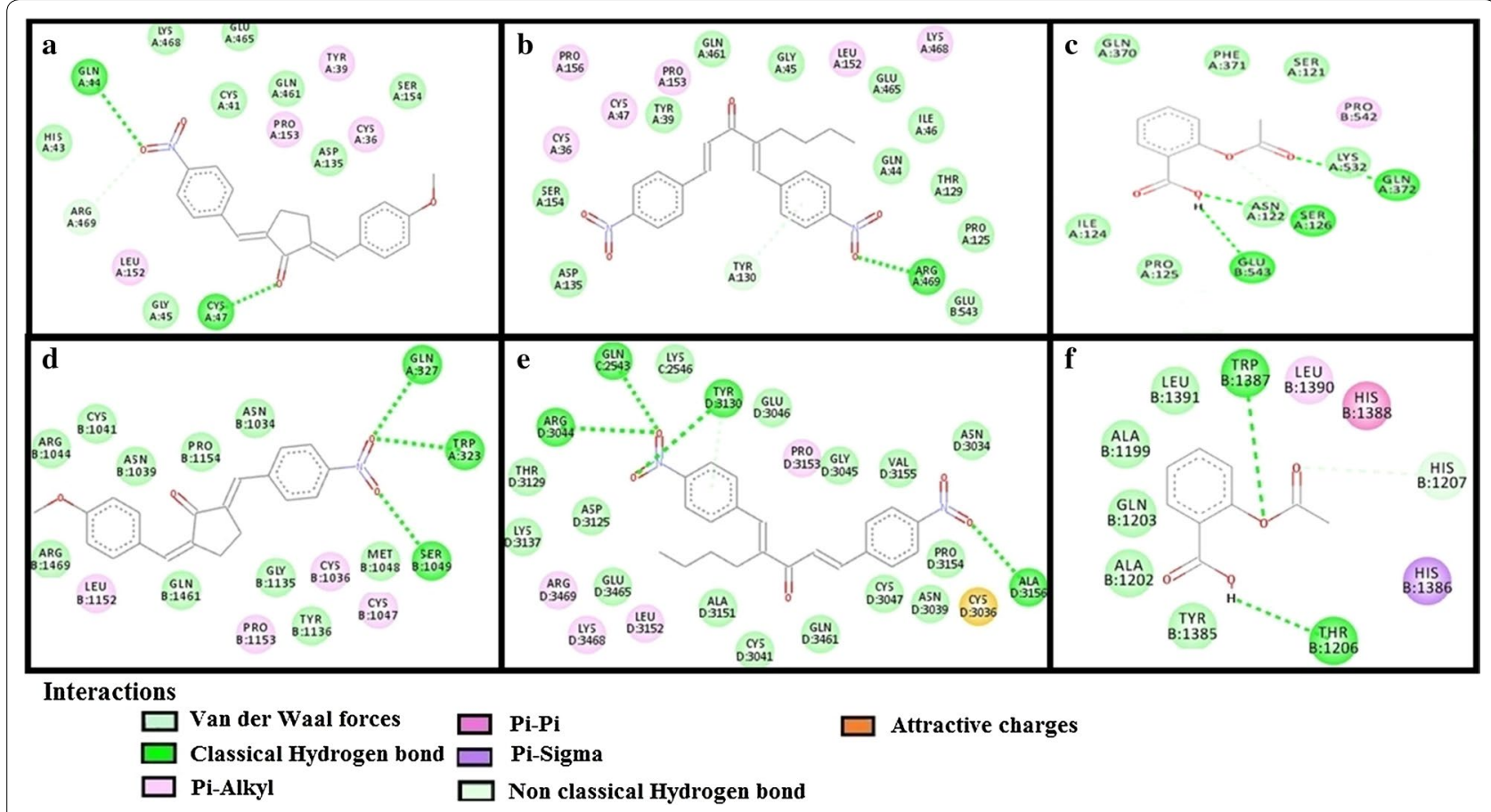

Fig. 4 a-c Represents interactions of ligands: (2E,5E)-2-(4-methoxybenzylidene)-5-(4-nitrobenzylidene) cyclopentanone (AK-1a), (1E,4E)-4-(4-nitrob enzylidene)-1-(4-nitrophenyl)oct-1-en-3-one (AK-2a) and aspirin with target: cyclooxygenase-1 (COX-1) respectively. $\mathbf{d}$-f Represents interactions of AK-1a, AK-2a and aspirin with target: cyclooxygenase-2 (COX-2) respectively, drawn through Biovia Discovery Studio Visualizer client 2016

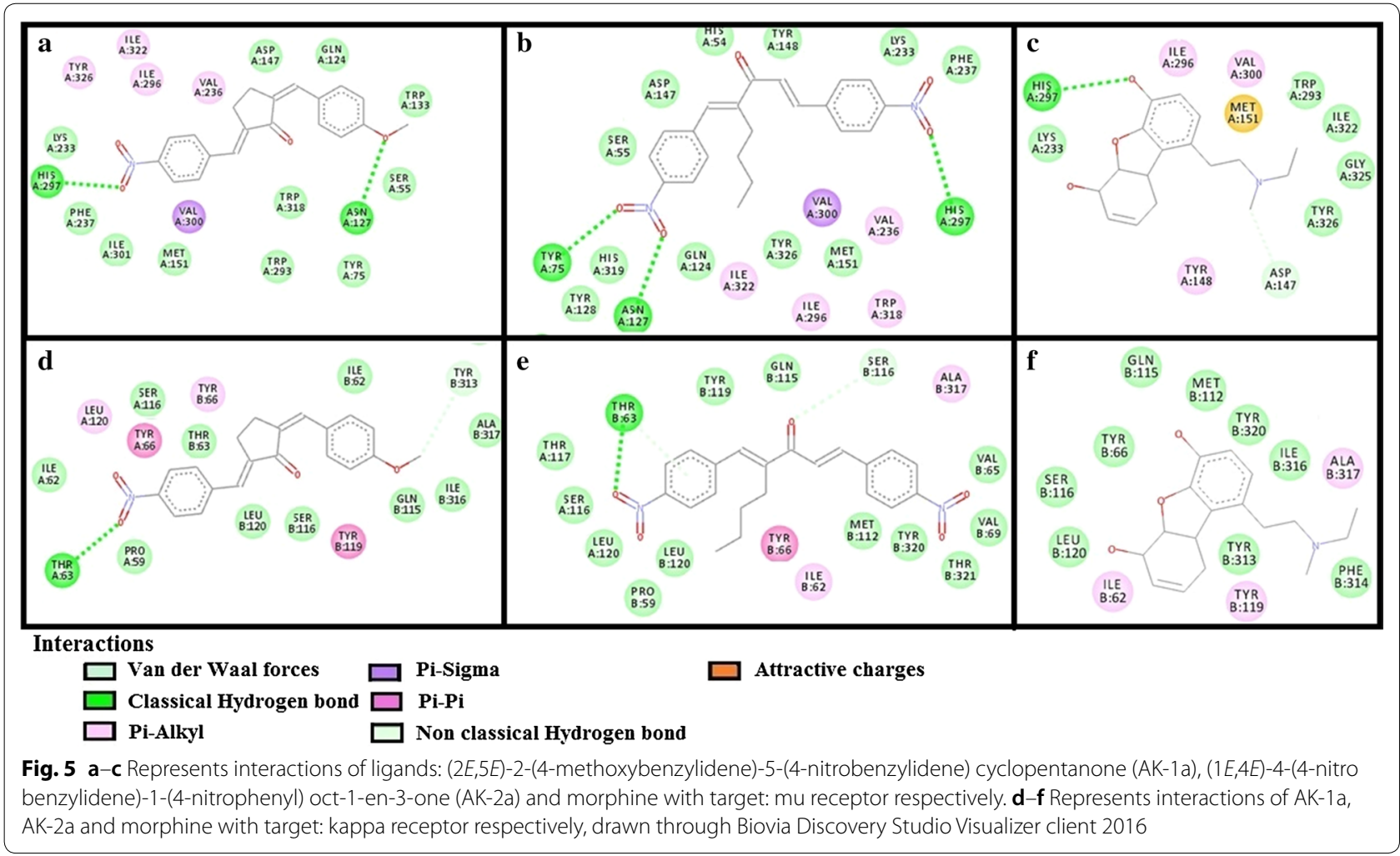




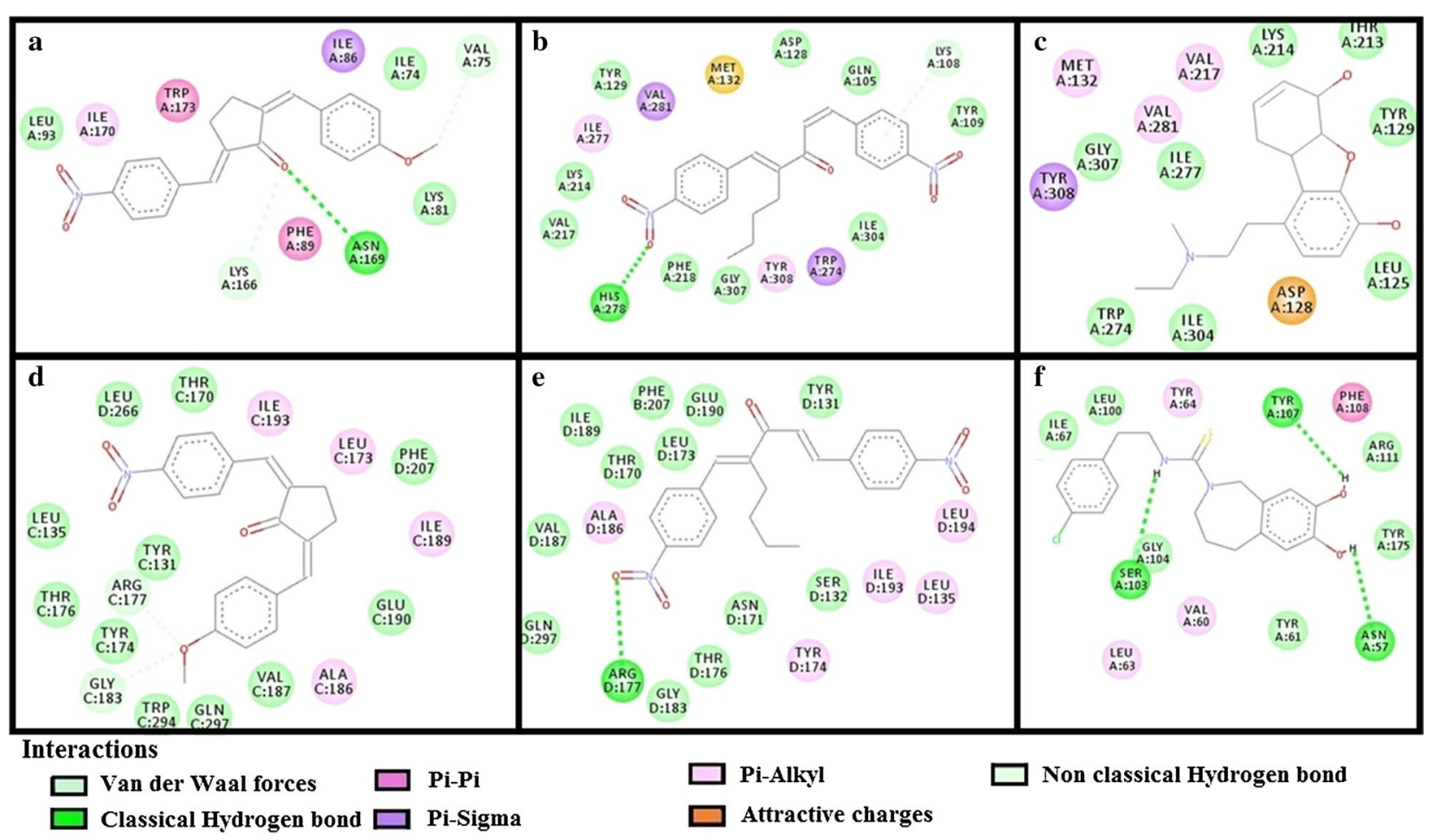

Fig. 6 a-c Represents interactions of ligands: (2E,5E)-2-(4-methoxybenzylidene)-5-(4-nitrobenzylidene) cyclopentanone (AK-1a), (1E,4E)-4-(4-nitro benzylidene)-1-(4-nitrophenyl) oct-1-en-3-one (AK-2a) and morphine with target: delta receptor respectively. $\mathbf{d}-\mathbf{f}$ Represents interactions of AK-1a, AK-2a and capsazepine with target: human capsaicin receptor (HCR) respectively, drawn through Biovia Discovery Studio Visualizer client 2016

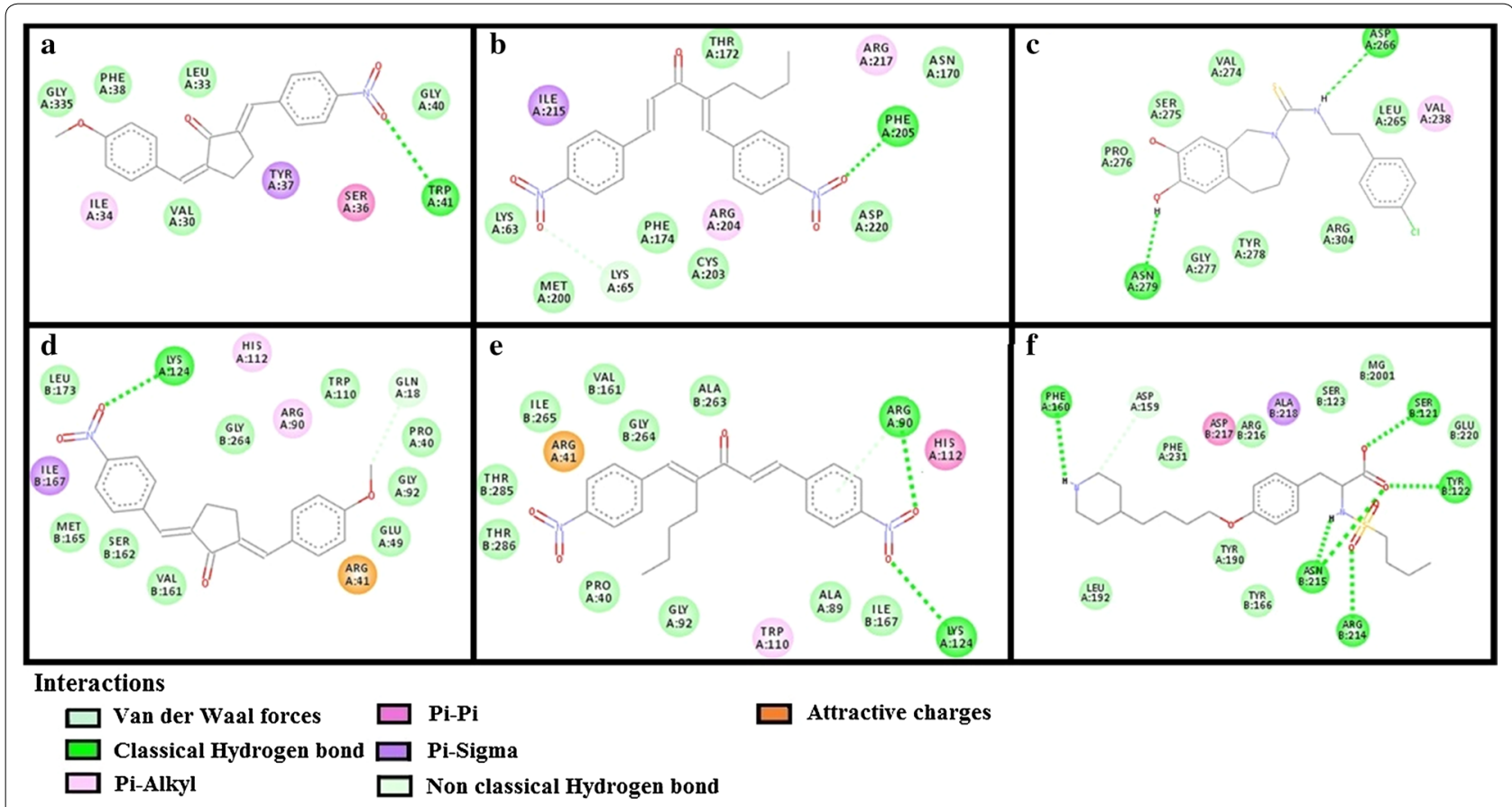

Fig. 7 a-c Represents interactions of ligands: (2E,5E)-2-(4-methoxybenzylidene)-5-(4-nitrobenzylidene) cyclopentanone (AK-1a), (1E,4E)-4-(4-nitrob enzylidene)-1-(4-nitrophenyl) oct-1-en-3-one (AK-2a) and capsazepine with target: purinoceptor-3 (P2X3) respectively. $\mathbf{d}$-f Represents interactions of AK-1a, AK-2a and tirofiban with target: glycoprotein-IIb/IIla (GP-IIb/IIla) respectively, drawn through Biovia Discovery Studio Visualizer client 2016 


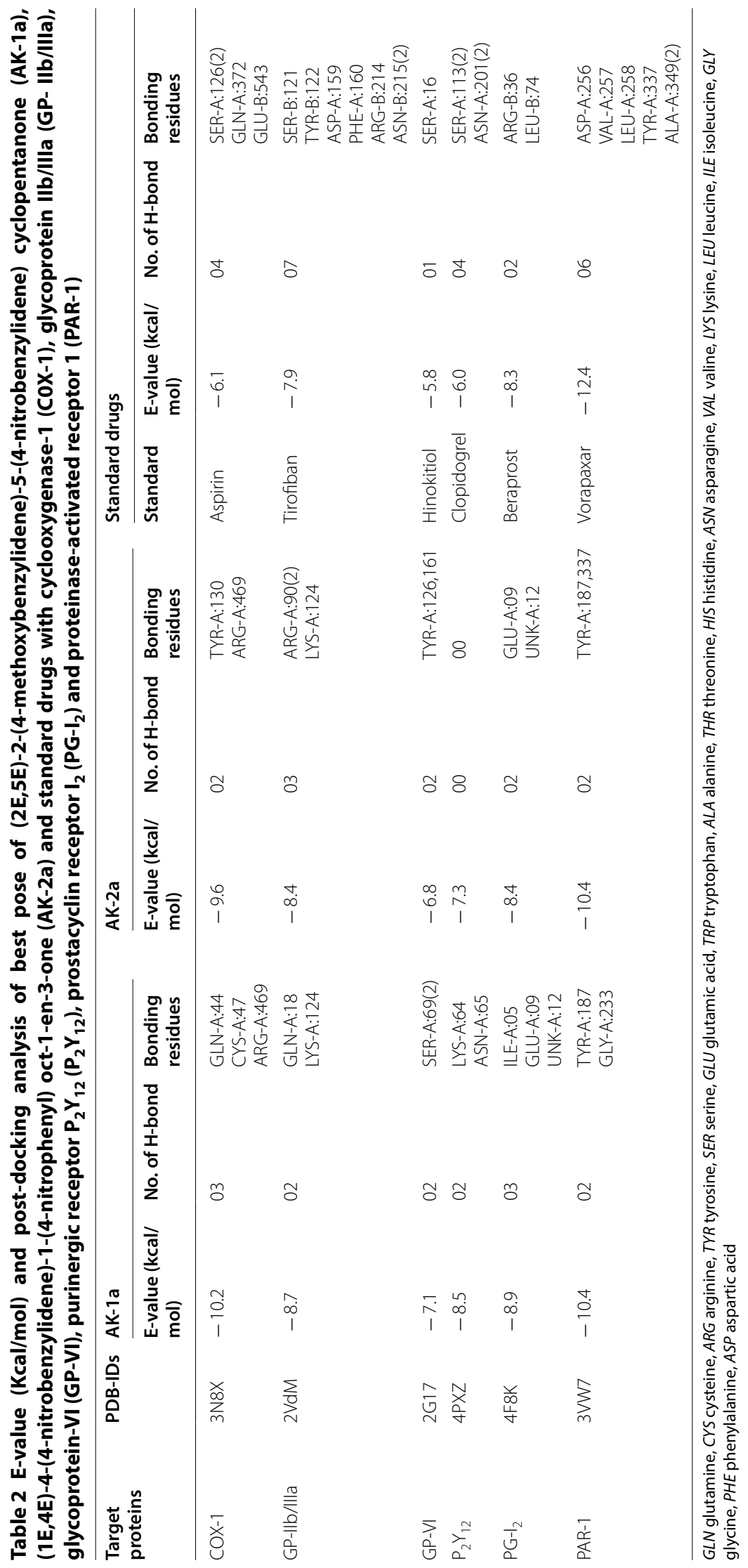




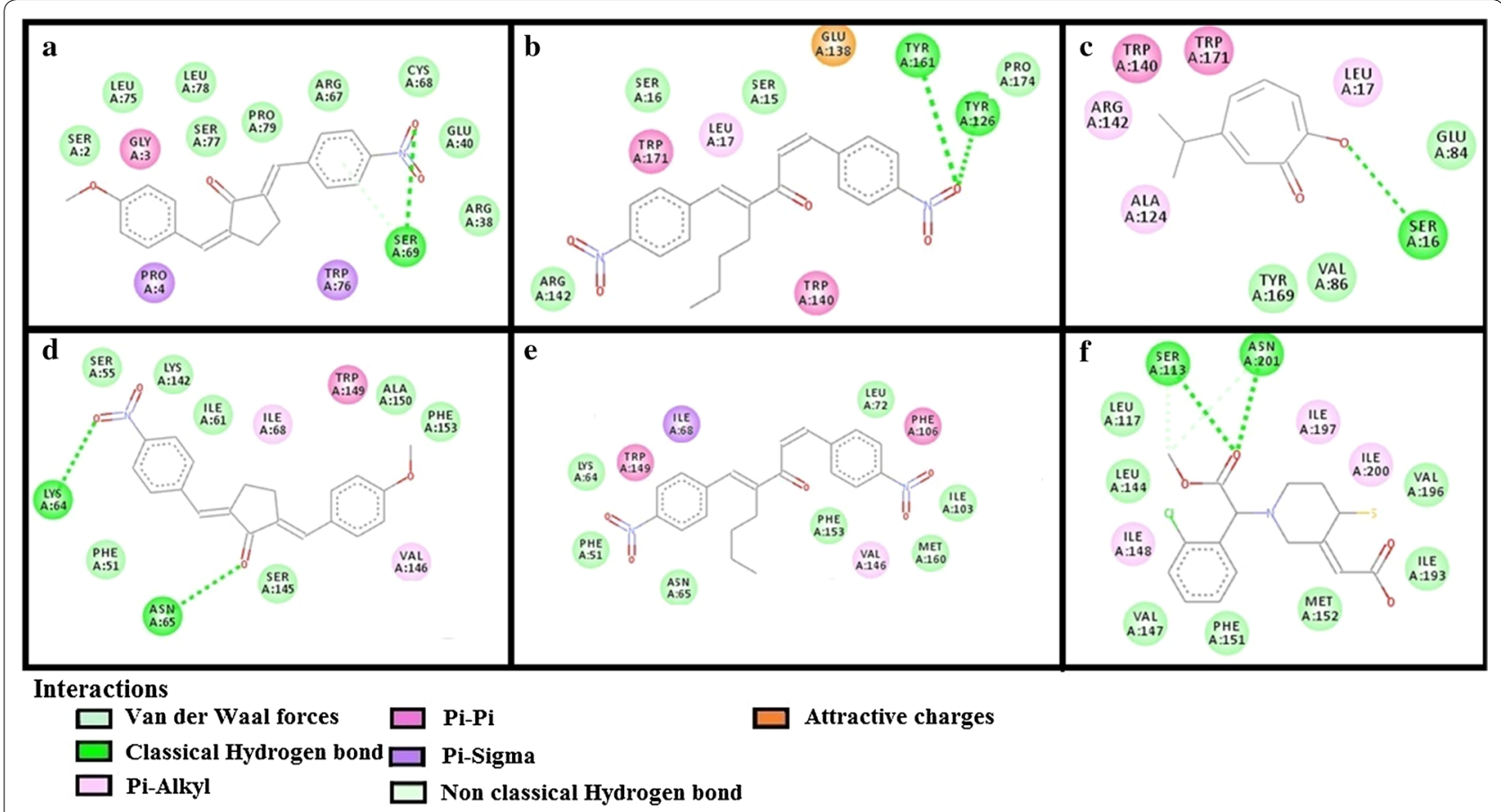

Fig. 8 a-c Represents interactions of ligands: (2E,5E)-2-(4-methoxybenzylidene)-5-(4-nitrobenzylidene) cyclopentanone (AK-1a), (1E,4E)-4-(4-nitro benzylidene)-1-(4-nitrophenyl) oct-1-en-3-one (AK-2a) and hinokitiol with target: glycoprotein-VI (GP-VI) respectively. $\mathbf{d}$-f represents interactions of AK-1a, AK-2a and clopidogrel with target: purinergic receptor $\left(P_{2} Y_{12}\right)$ respectively, drawn through Biovia Discovery Studio Visualizer client 2016

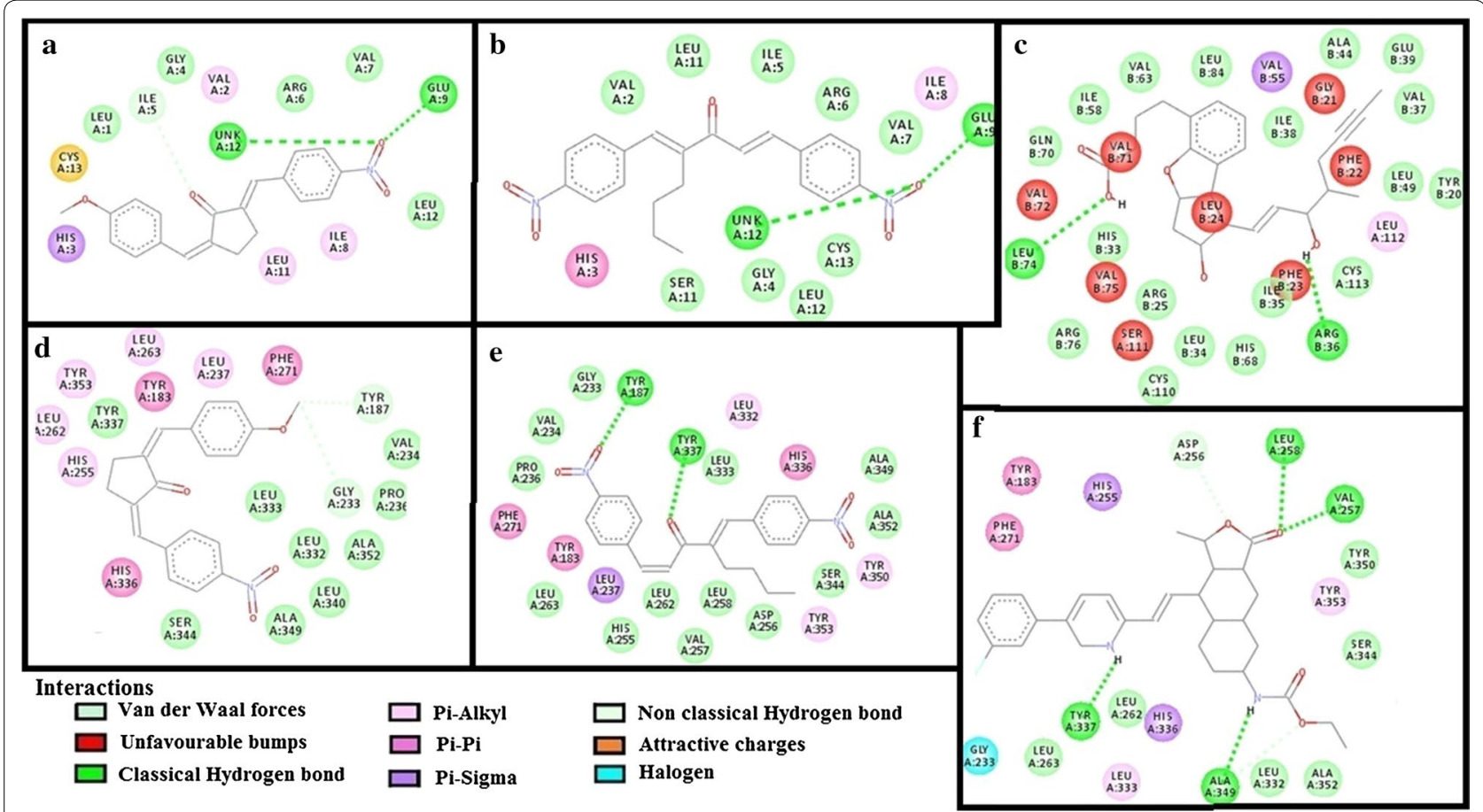

Fig. 9 a-c Represents interactions of ligands: (2E,5E)-2-(4-methoxybenzylidene)-5-(4-nitrobenzylidene)cyclopentanone (AK-1a), (1E,4E)-4-(4-nit robenzylidene)-1-(4-nitrophenyl) oct-1-en-3-one (AK-2a) and beraprost with target: prostacyclin receptor $\mathrm{I}_{2}\left(\mathrm{PG}-\mathrm{I}_{2}\right)$ respectively. $\mathbf{d}$-f Represents interactions of AK-1a, AK-2a and vorapaxar with target: proteinase-activated receptor 1 (PAR-1) respectively, drawn through Biovia Discovery Studio Visualizer client 2016 


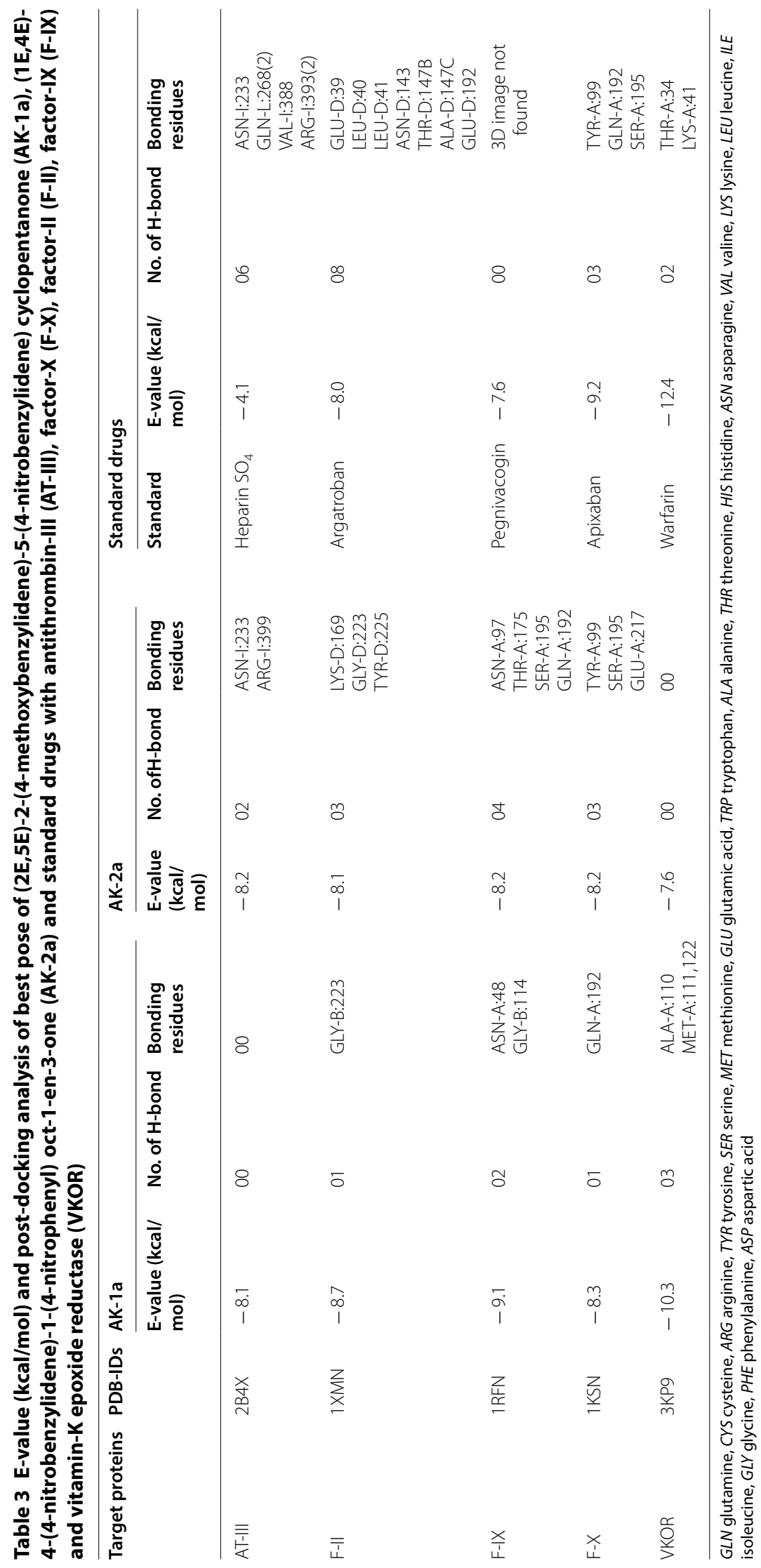




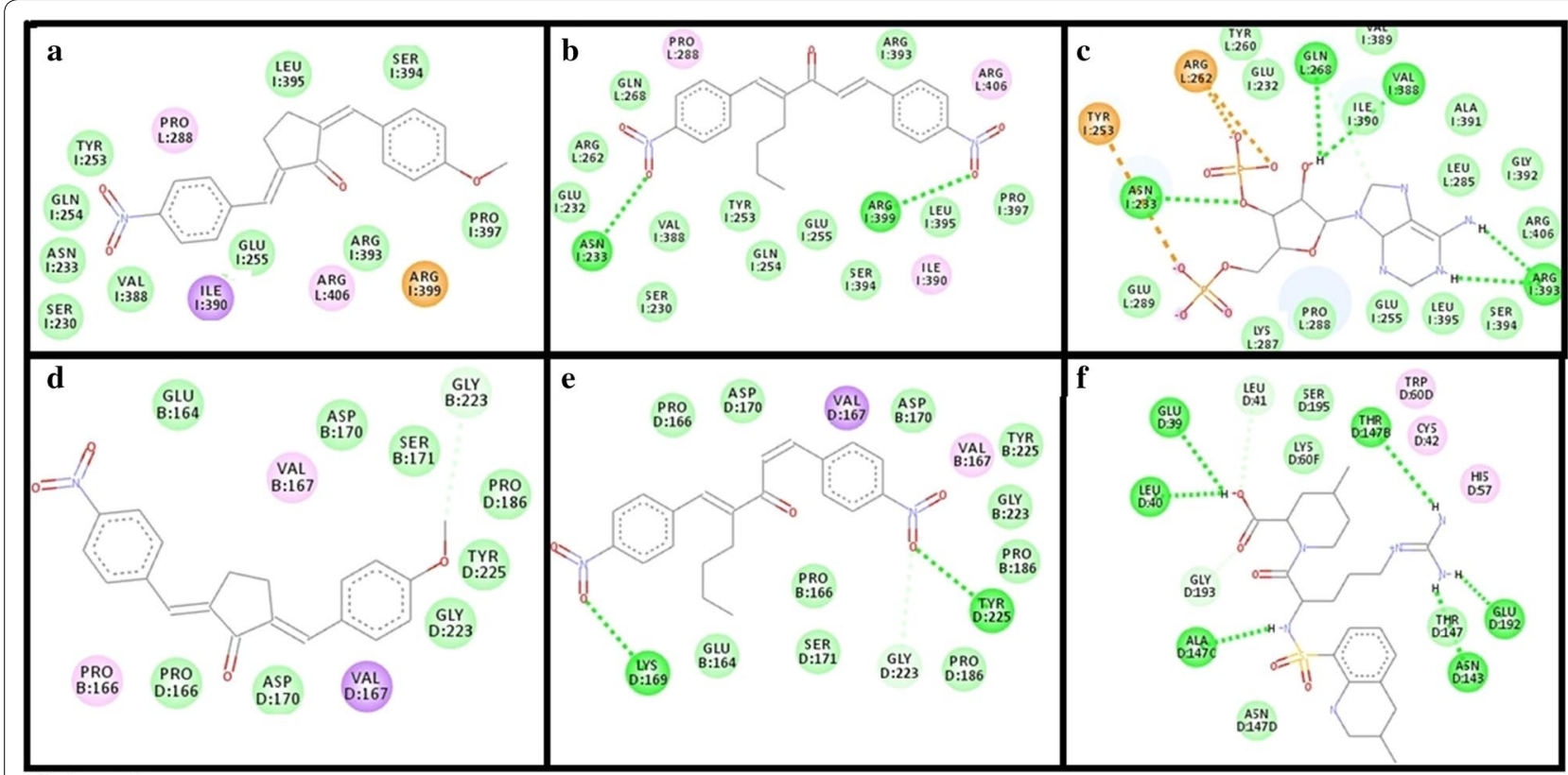

Interactions

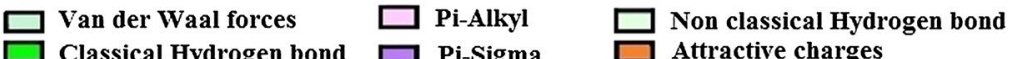

$\square$ Classical Hydrogen bond $\square$ Pi-Sigma $\square$ Attractive charges

Fig. 10 a-c Represents interactions of ligands: (2E,5E)-2-(4-methoxybenzylidene)-5-(4-nitrobenzylidene)cyclopentanone (AK-1a), (1E,4E)-4-(4-nit robenzylidene)-1-(4-nitrophenyl) oct-1-en-3-one (AK-2a) and heparin sulphate with target: antithrombin-III (AT-III) respectively. d-f Represents interactions of AK-1a, AK-2a and argatroban with target: factor-II (F-II) respectively, drawn through Biovia Discovery Studio Visualizer client 2016

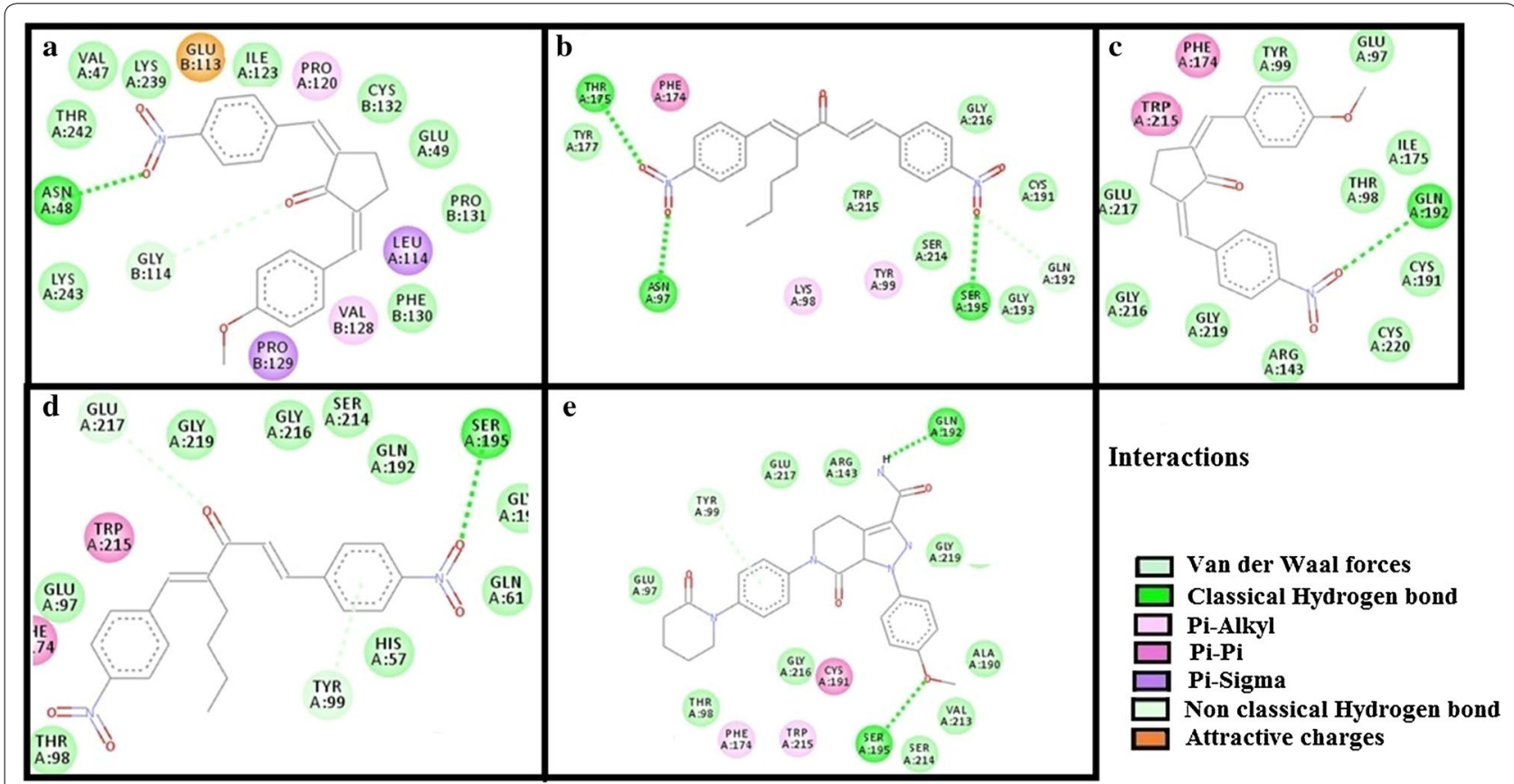

Fig. 11 a, b Represents interactions of ligands: (2E,5E)-2-(4-methoxybenzylidene)-5-(4-nitrobenzylidene) cyclopentanone (AK-1a) and (1E,4E)-4-(4nitrobenzylidene)-1-(4-nitrophenyl) oct-1-en-3-one (AK-2a) with target factor-IX (F-IX) respectively. c-e Represents interaction of AK-1a, AK-2a and apixaban with target: factor-X (F-X) respectively, drawn through Biovia Discovery Studio Visualizer client 2016 

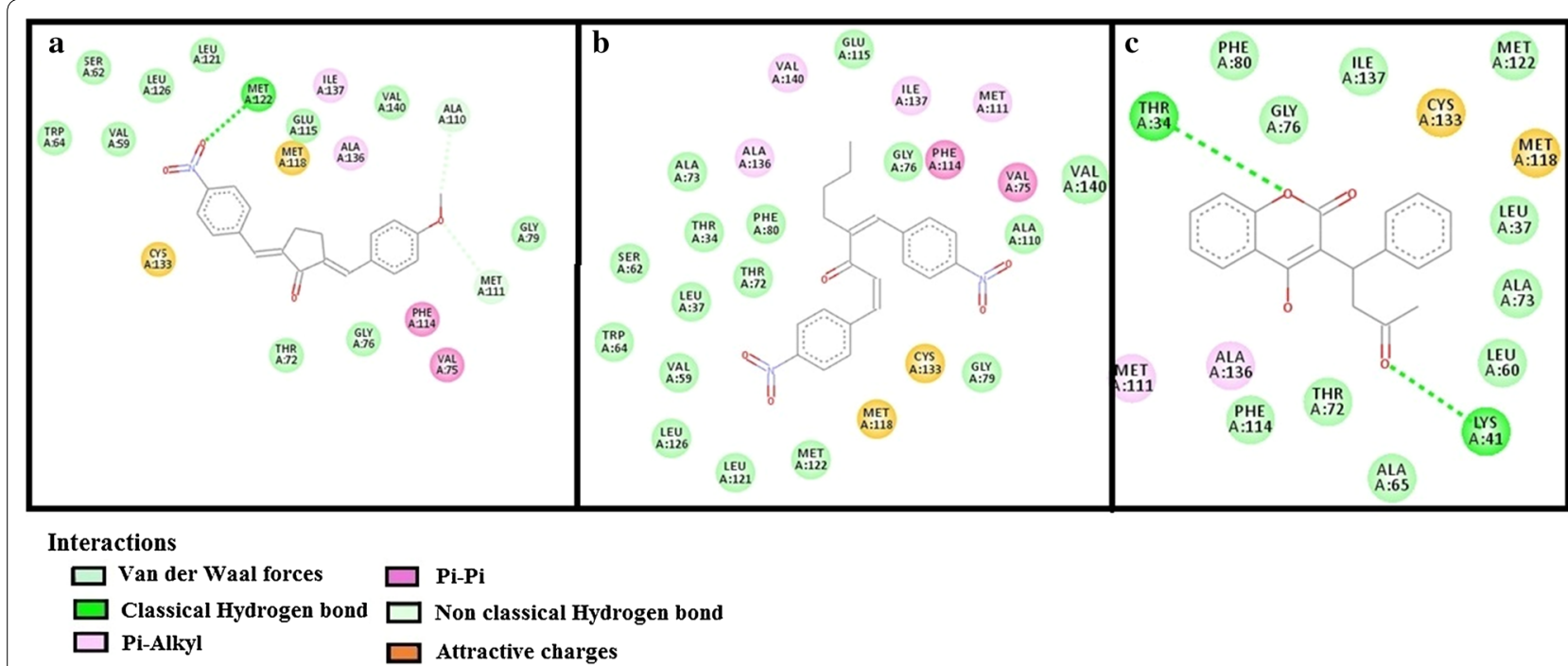

Fig. 12 a-c Represents interactions of ligands: (2E,5E)-2-(4-methoxybenzylidene)-5-(4-nitrobenzylidene) cyclopentanone (AK-1a), (1E,4E)-4-(4-nitr obenzylidene)-1-(4-nitrophenyl)oct-1-en-3-one (AK-2a) and warfarin with target: vitamin-K epoxide reductase (VKOR) respectively, drawn through Biovia Discovery Studio Visualizer client 2016

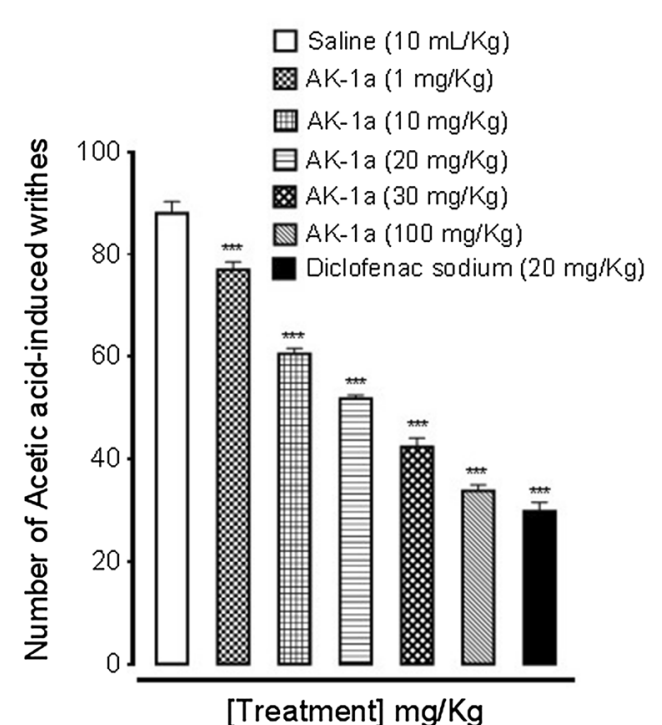

[Treatment] $\mathrm{mg} / \mathrm{Kg}$

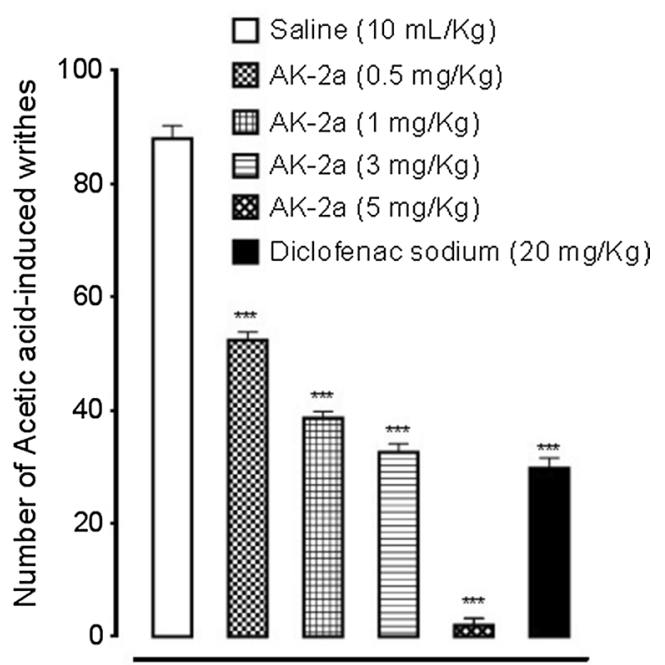

[Treatment] $\mathrm{mg} / \mathrm{Kg}$

Fig. 13 Effect of (2E,5E)-2-(4-methoxybenzylidene)-5-(4-nitrobenzylidene) cyclopentanone (AK-1a), (1E,4E)-4-(4-nitrobenzylidene)-1-(4-nitrophenyl) oct-1-en-3-one (AK-2a) and diclofenac sodium on acetic acid-induced writhes in mice. Data expressed as mean $\pm S E M, n=5$. ${ }^{* * *} P<0.001$ vs. saline group, one way ANOVA with post hoc Tukey's test

$10.080 \pm 0.105,11.23 \pm 0.21$ and $12.06 \pm 0.15 \mathrm{~s}(P<0.001$ vs. saline group) respectively. The latency time of AK-2a $(3 \mathrm{mg} / \mathrm{kg})$ treated group at $0,30,60,90$ and $120 \mathrm{~min}$ were $6.39 \pm 0.18,8.93 \pm 0.03$ ( $P<0.05$ vs. saline group), $10.70 \pm 0.05,11.70 \pm 0.12$ and $14.49 \pm 0.25 \mathrm{~s} \quad(P<0.001$ vs. saline group) respectively. The latency time of AK-2a $(5 \mathrm{mg} / \mathrm{kg})$ treated group at $0,30,60,90$ and $120 \mathrm{~min}$ were $7.96 \pm 0.15,9.16 \pm 0.04,11.36 \pm 0.23,12.99 \pm 0.15$ and
$15.69 \pm 0.19 \mathrm{~s}(P<0.001 \mathrm{vs}$. saline group $)$ respectively as shown in Fig. 15.

\section{Effect on AA-induced platelet aggregation inhibition}

AK-1a at 1, 3, 10, 30, 100, 300 and $1000 \mu \mathrm{M}$ concentrations, inhibited AA-induced platelet aggregation to $2.3 \pm 0.06,7.2 \pm 0.06,20.4 \pm 0.06,33.2 \pm 0.14,55.6 \pm 0.20$, $67.1 \pm 0.15$ and $88.5 \pm 0.18 \%$ respectively with $\mathrm{IC}_{50}$ 


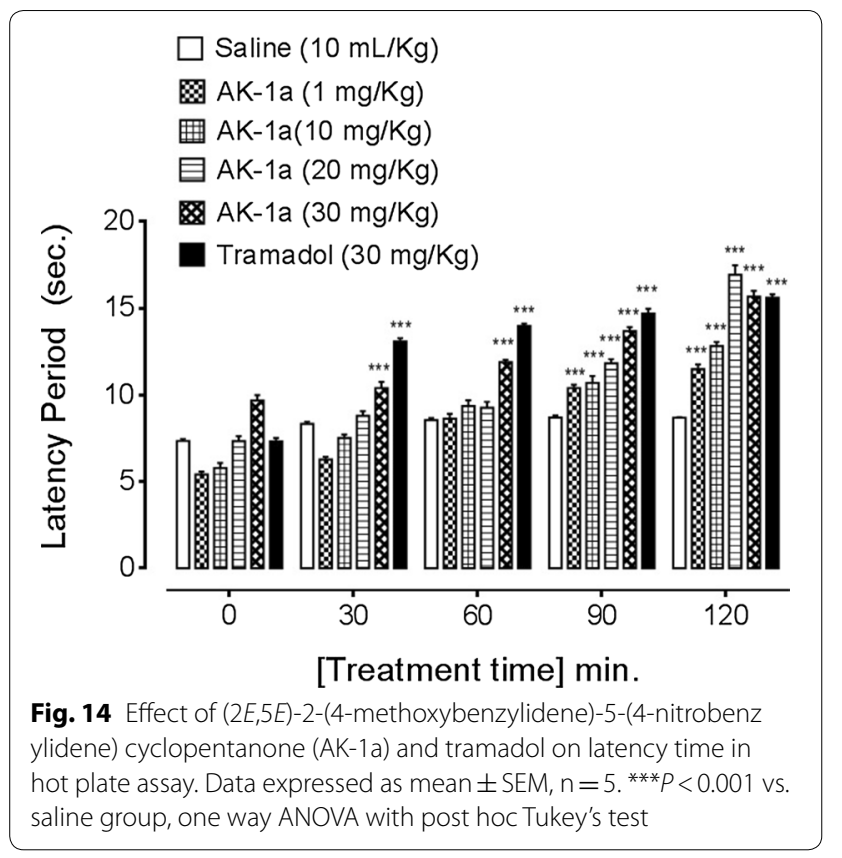

value of $65.2 \mu \mathrm{M}$. At same concentrations AK-2a inhibited AA-induced platelet aggregation to $4.3 \pm 0.07$, $10.5 \pm 0.09,28 \pm 0.15,42.7 \pm 0.22,62.2 \pm 0.08,78.9 \pm 0.19$ and $89.8 \pm 0.13 \%$ respectively with $\mathrm{IC}_{50}$ value of $37.7 \mu \mathrm{M}$. Aspirin inhibited AA-induced platelet aggregation to $27.2 \pm 0.18,36 \pm 0.09,50.1 \pm 0.16,59.7 \pm 0.09$ and $100 \%$ respectively with $\mathrm{IC}_{50}$ value of $10.01 \mu \mathrm{M}$, as shown in Table 4.

\section{Effect on ADP-induced platelet aggregation inhibition}

AK-1a at 1, 3, 10, 30, 100, 300 and $1000 \mu \mathrm{M}$ concentrations, inhibited ADP-induced platelet aggregation to $1.81 \pm 0.04,4.4 \pm 0.04,13.4 \pm 0.06,22.4 \pm 0.04,31 \pm 0.06$, $42.6 \pm 0.06$ and $54.1 \pm 0.06 \%$ respectively with $\mathrm{IC}_{50}$ value of $750.4 \mu \mathrm{M}$. At same concentrations AK-2a inhibited ADP-induced platelet aggregation to $4.4 \pm 0.04$, $4.4 \pm 0.07,14.2 \pm 0.02,18.6 \pm 0.06,30.2 \pm 0.07,48.3 \pm 0.12$ and $56.8 \pm 0.06 \%$ respectively with $\mathrm{IC}_{50}$ value of $422 \mu \mathrm{M}$. Aspirin inhibited ADP-induced platelet aggregation to $3.6 \pm 0.07,6.2 \pm 0.09,19.1 \pm 0.07,25 \pm 0.06,32.8 \pm 0.10$, $49.8 \pm 0.12, \quad 49.8 \pm 0.12$ and $56.9 \pm 0.18 \%$ respectively with $\mathrm{IC}_{50}$ value of $308.4 \mu \mathrm{M}$, as shown in Table 4 .

\section{Effect on PRT}

At $30,100,300$ and $1000 \mu \mathrm{M}$ concentrations, AK-1a increased coagulation time to $137 \pm 2.12,182.8 \pm 5.59$, $224.6 \pm 8.37$ and $284 \pm 9.46 \mathrm{~s}(P<0.001$ vs. saline group $)$ respectively. AK-2a increased coagulation time to $128 \pm 2.16, \quad 150.6 \pm 2.29, \quad 186 \pm 3.25$ and $223 \pm 4.47 \mathrm{~s}$ $(P<0.001$ vs. saline group) respectively as shown in

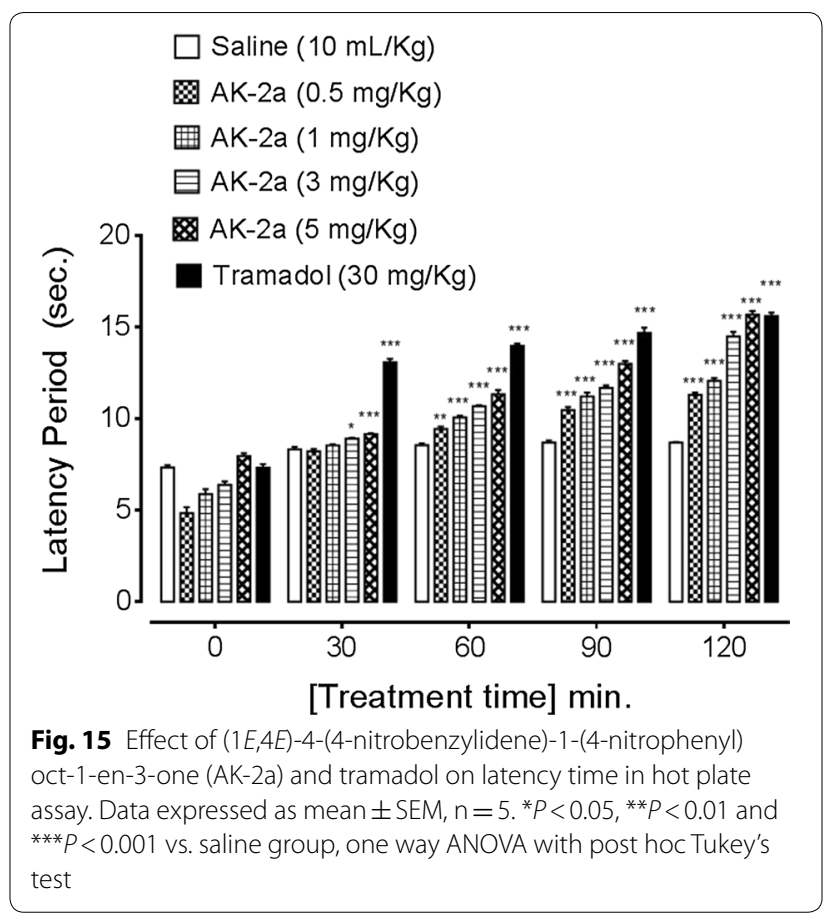

Fig. 16. At $440 \mu \mathrm{M}$ concentration, heparin increased coagulation time to $379.40 \pm 9.17 \mathrm{~s}(P<0.001$ vs. saline group).

\section{Effect on BT}

At 100,300 and $1000 \mu \mathrm{g} / \mathrm{kg}$ doses, AK-1a increased BT to $45.25 \pm 1.75,59.25 \pm 1.65$ ( $P<0.01$ vs. saline group) and $77.75 \pm 3.32 \mathrm{~s}(P<0.001 \mathrm{vs}$. saline group $)$ respectively. AK-2a increased BT to $75.25 \pm 3.56(P<0.01$ vs. saline group $), 91.50 \pm 11.11$ and $120.50 \pm 1.44 \mathrm{~s}(P<0.001$ vs. saline group) respectively as shown in Fig. 17. Heparin at $40 \mu \mathrm{g} / \mathrm{kg}$ dose, increased BT to $170.75 \pm 7.75 \mathrm{~s}(P<0.001$ vs. saline group).

\section{Discussion}

In this study, we synthesized and chemically characterized two new dibenzylidene ketone derivatives. The in-silico study carried out to get an initial information about the affinity of any compound before the start of in-vivo experiment. Docking is a preliminary tool used to check the affinity of ligands to their respective protein targets. Molecular docking has an ambient role in drug discovery and development including structure based evaluation and finding target specificity and binding affinity [25]. These interactions may exist in the form of hydrogen bonds, hydrophobic interactions and Van der Waal forces. Auto Dock Vina program was used through PyRx. It uses gradient optimization 
Table 4 Inhibitory effect of (2E,5E)-2-(4-methoxybenzylidene)-5-(4-nitrobenzylidene) cyclopentanone (AK-1a) and (1E,4E)-4-(4-nitrobenzylidene)-1-(4-nitrophenyl)oct-1-en-3-one (AK-2a) and aspirin against arachidonic acid (AA) and adenosine diphosphate (ADP)-induced platelet aggregation

\begin{tabular}{|c|c|c|c|c|c|c|c|c|c|}
\hline \multirow[t]{2}{*}{ Treatment } & \multirow[t]{2}{*}{ Agonist } & \multicolumn{7}{|c|}{ Inhibition of platelet aggregation (\%) \pm SEM } & \multirow[t]{2}{*}{$\mathrm{IC}_{50}(\mu \mathrm{M})$} \\
\hline & & $1 \mu \mathrm{M}$ & $3 \mu \mathrm{M}$ & $10 \mu \mathrm{M}$ & $30 \mu \mathrm{M}$ & $100 \mu \mathrm{M}$ & $300 \mu \mathrm{M}$ & $1000 \mu \mathrm{M}$ & \\
\hline \multirow[t]{2}{*}{ AK-1a } & AA & $2.3 \pm 0.06$ & $7.2 \pm 0.06$ & $20.4 \pm 0.06$ & $33.2 \pm 0.14$ & $55.6 \pm 0.20$ & $67.1 \pm 0.15$ & $88.5 \pm 0.18$ & 65.2 \\
\hline & ADP & $1.81 \pm 0.04$ & $4.4 \pm 0.04$ & $13.4 \pm 0.06$ & $22.4 \pm 0.04$ & $31 \pm 0.06$ & $42.6 \pm 0.06$ & $54.1 \pm 0.06$ & 750.4 \\
\hline \multirow[t]{2}{*}{ AK-2a } & AA & $4.3 \pm 0.07$ & $10.5 \pm 0.09$ & $28 \pm 0.15$ & $42.7 \pm 0.22$ & $62.2 \pm 0.08$ & $78.9 \pm 0.19$ & $89.8 \pm 0.13$ & 37.7 \\
\hline & ADP & $4.4 \pm 0.04$ & $4.4 \pm 0.07$ & $14.2 \pm 0.02$ & $18.6 \pm 0.06$ & $30.2 \pm 0.07$ & $48.3 \pm 0.12$ & $56.8 \pm 0.06$ & 422 \\
\hline \multirow[t]{2}{*}{ Aspirin } & AA & $27.2 \pm 0.18$ & $36 \pm 0.09$ & $50.1 \pm 0.16$ & $59.7 \pm 0.09$ & $100 \pm 0$ & $100 \pm 0$ & $100 \pm 0$ & 10.01 \\
\hline & ADP & $3.6 \pm 0.07$ & $6.2 \pm 0.09$ & $19.1 \pm 0.07$ & $25 \pm 0.06$ & $32.8 \pm 0.10$ & $49.8 \pm 0.12$ & $56.9 \pm 0.18$ & 308.4 \\
\hline
\end{tabular}

Values shown as mean $\pm S E M, n=4$

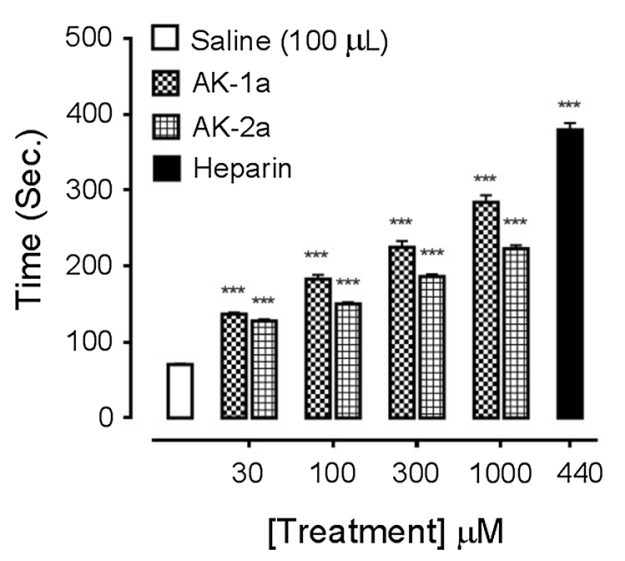

Fig. 16 Bar chart showing increase in plasma recalcification time (PRT) caused by different concentrations of (2E,5E)-2-(4-methoxybe nzylidene)-5-(4-nitrobenzylidene) cyclopentanone (AK-1a), (1E,4E)4-(4-nitrobenzylidene)-1-(4-nitrophenyl) oct-1-en-3-one (AK-2a) and heparin. Data expressed as mean $\pm \mathrm{SEM}, \mathrm{n}=5$, ${ }^{* * *} P<0.001$ vs. saline group, one way ANOVA with post hoc Tukey's test

method and it improves accuracy of binding mode predictions [26]. Hydrogen bonding is reported to be very significant in the formation of ligand protein complex [27]. Further we assessed affinity of ligands through E-value and number of hydrogen bonds against protein targets that influence analgesic, antiplatelet and anticoagulant effect. AK-1a and AK-2a showed highest binding affinity against PAR-1. AK-1a order of binding affinity against target proteins was found as: $\quad \mathrm{VKOR}>\mathrm{COX}-1>\mathrm{COX}-2>\mathrm{F}-\mathrm{IX}>\mathrm{PG}-\mathrm{I}_{2}>\mathrm{HCR}>$ $\mathrm{mu}$ receptor $>\mathrm{GPIIb} / \mathrm{IIa}>\mathrm{F}-\mathrm{II}>\mathrm{P}_{2} \mathrm{Y}_{12}>$ kappa receptor $>$ F-X $>$ delta receptor $>$ AT-III $>$ P2X $>$ GP-VI. AK-2a order of binding affinity against target proteins was found as: COX-1>COX-2 $>\mathrm{HCR}>\mathrm{mu}$ receptor $>$ kappa receptor $>\mathrm{GPIIb} /$ IIIa $>$ PG-I ${ }_{2}>$ AT-III $>$ F-IX $>$ F-X $>$ F-II $>$ delta receptor $>$ VKOR $>P_{2} Y_{12}>P_{2} X_{3}>$ GPVI. We can infer that our compounds have analgesic, antiplatelet and anticoagulant actions. The analgesic activity was studied using two standard protocols i.e. acetic acid induced writhing method and hot plate assay to evaluate the peripheral and central effects of analgesia [28]. Basically writhing is an abdominal constriction caused by the release of different types of mediators after the i.p injection of acetic acid. This noxious response can be prevented by drugs which have the ability to stop the synthesis of these chemicals. The reduction in the number of writhes in treated group explains the same phenomenon of blocking the production of mediators by inhibiting COX-2 by the test compounds. Analgesic actions of AK-1a and AK-2a are proposed as inhibition of prostanoid release from cyclooxygenase involved in visceral nociception induced by acetic acid [29]. The central nociceptive effects were validated through hotplate assay [30]. AK-1a and AK-2a showed dosedependent analgesic response, while AK-2a is found to be potent, as dose $\geq 10 \mathrm{mg} / \mathrm{kg}$ cannot be used for the analgesic activity. Significant response against acetic acid-induced writhing and hotplate assay by AK-1a and AK-2a explains central as well as peripheral activity of dibenzylidene ketone derivatives [31]. In acetic acid-induced writhing at higher dose AK-2a showed significant response, it can be further checked for antiinflammatory response. The nociceptive behavior in the acetic acid-induced writhing test occurs due to synthesis of pain mediators including prostaglandins due to induction of COX-2 that results increased in pain sensitivity after acetic acid injection [32, 33]. Acetic acid produces nociception by releasing chemical mediators such as serotonin, histamine, prostaglandins, bradykinins and substance $\mathrm{P}$ due to induction of COX-2 that results in increased pain sensitivity after acetic acid injection. The acetic-induced writhing test is also 


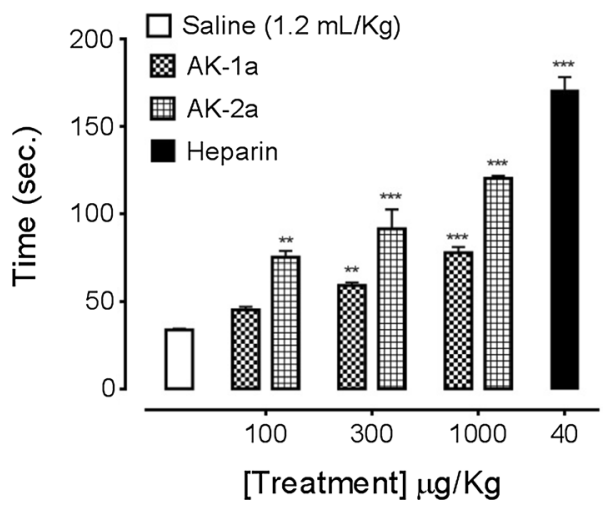

Fig. 17 Bar chart showing increase in tail bleeding time (BT) caused by different doses of (2E,5E)-2-(4-methoxybenzylidene)-5-(4-nitro benzylidene) cyclopentanone (AK-1a), (1E,4E)-4-(4-nitrobenzylid ene)-1-(4-nitrophenyl) oct-1-en-3-one (AK-2a) and heparin in mice. Data expressed as mean \pm SEM, $n=4,{ }^{* *} P<0.01$ and ${ }^{* *} P<0.001$ vs. saline group, one way ANOVA with post hoc Tukey's test

sensitive to adrenoceptor agonists and opioid agonists which through appropriate receptor stimulation in the peritoneal cavity cause reduction in pain perception $[34,35]$. This test involves both central and peripheral mechanisms in the early phase of the test [36]. However, hot plate test is regarded as a suitable model for the involvement of central mechanisms [37, 38]. PAR-1 activation leads to stimulation of arachidonic acid release and thrombin signaling. Arachidonic acid enhances the activation of platelet aggregation cascade $[39,40]$. This can be a proposed mechanism of action for AK-1a and AK-2a as antiplatelet and anticoagulant agents. As per computational study results, both can be a potential antagonist of PAR-1 which was further validated. Curcumin analogues inhibit platelet aggregation and repress thrombosis. Dibenzylidene ketone derivatives used in this study, having ketone moiety showed significant antiplatelet and anticoagulant response [41] presence of methoxy group in AK-1a enhanced its biological activity [42]. Previous studies revealed role of curcumin derivatives as a vitamin $\mathrm{k}$ antagonist [43], so as these dibenzylidene ketone derivatives. Anticoagulant actions of AK-1a and AK-2a were also validated by the presence of hydrophobic groups [44].

\section{Conclusions}

The present study reports $t$ newly synthesized dibenzylidene ketone derivatives AK-1a and AK-2a showed high binding affinities against different protein targets involved in mediation of pain, platelet aggregation and blood coagulation process. The pharmacological investigations based on in-silico, in-vitro and in-vivo studies revealed their analgesic, antiplatelet and anticoagulant actions. These are promising findings, since the production of dibenzylidene compounds is a simple, cheap and feasible process.

\section{Authors' contributions}

All authors listed have made a substantial, direct and intellectual contribution to the work, and approved it for publication. TA carried out the computational studies, experimental work, analyzed the data and documentation. AK and FA supervised the research project. EF and AK synthesized dibenzylidene ketone derivatives. MA and ZD revised the final manuscript. All authors read and approved the final manuscript.

\section{Author details \\ ${ }^{1}$ Riphah Institute of Pharmaceutical Sciences, Riphah International University, Islamabad, Pakistan. ${ }^{2}$ LaBioMMi, Department of Chemistry, Federal Univer- sity of São Carlos, CP 676, São Carlos, SP 13565-905, Brazil. ${ }^{3}$ Department of Chemistry, Woman University Swabi, GulooDehri, Topi Road, Swabi, KP 23340, Pakistan. ${ }^{4}$ Basic Sciences Department, College of Science and Health Professions-(COSHP-J), King Saud bin Abdulaziz University for Health Sciences, Jeddah, Saudi Arabia. ${ }^{5}$ Present Address: Department of Pharmacy, Capital University of Science and Technology, Islamabad, Pakistan.}

\section{Acknowledgements}

The authors are thankful to Riphah Academy of Research and Education, Riphah International University, for partial financial support of the study.

\section{Competing interests}

The authors declare that they have no competing interests.

Funding

There are no specific funding for the study.

\section{Publisher's Note}

Springer Nature remains neutral with regard to jurisdictional claims in published maps and institutional affiliations.

Received: 9 March 2018 Accepted: 29 November 2018

Published online: 06 December 2018

\section{References}

1. Loeser JD, Melzack R (1999) Pain: an overview. Lancet 353(9164):16071609. https://doi.org/10.1016/S0140-6736(99)01311-2

2. Zulfiker A, Rahman MM, Hossain MK, Hamid K, Mazumder M, Rana MS (2010) In vivo analgesic activity of ethanolic extracts of two medicinal plants-Scoparia dulcis L. and Ficus racemosa Linn. Biol Med 2:42-48

3. O'brien J (1995) Platelet activation at high and low shear is followed by inactivation: the clinical relevance. Platelets 6:242-243. https://doi. org/10.3109/09537109509078461

4. Warfarin Antiplatelet Vascular Evaluation Trial Investigators (2007) Oral anticoagulant and antiplatelet therapy and peripheral arterial disease. N Engl J Med 2007:217-227. https://doi.org/10.1056/NEJMoa065959

5. Mackman N (2008) Triggers, targets and treatments for thrombosis. Nature 451:914. https://doi.org/10.1038/nature06797

6. Dahlbäck B (2000) Blood coagulation. Lancet 355:1627-1632. https://doi. org/10.1016/S0140-6736(00)02225-X

7. Maynard J, Heckman C, Pitlick F, Nemerson Y (1975) Association of tissue factor activity with the surface of cultured cells. J Clin Invest 55:814. https ://doi.org/10.1172/JCl107992

8. Davie EW, Fujikawa K, Kisiel W (1991) The coagulation cascade: initiation, maintenance, and regulation. Biochem 30:10363-10370. https://doi. org/10.1021/bi00107a001

9. Schlitt A, Rubboli A, Airaksinen KEJ, Lip GY (2013) Antiplatelet therapy and anticoagulants. Lancet 382(9886):24-25

10. Shen L, Ji H-F (2007) Theoretical study on physicochemical properties of curcumin. Spectrochim Acta Part A Mol Biomol Spectrosc 67:619-623. https://doi.org/10.1016/j.saa.2006.08.018 
11. Hatcher H, Planalp R, Cho J, Torti F, Torti S (2008) Curcumin: from ancient medicineto current clinical trials. Cell Mol Life Sci 65:1631-1652. https:// doi.org/10.1007/s00018-008-7452-4

12. Srivastava R, Dikshit M, Srimal R, Dhawan B (1985) Anti-thrombotic effect of curcumin. Thromb Res 40:413-417

13. Srivastava K (1989) Extracts from two frequently consumed spicescumin (Cuminum cyminum) and turmeric (Curcuma longa)_-inhibit platelet aggregation and alter eicosanoid biosynthesis in human blood platelets. Prostaglandins Leukot Essent Fatty Acids 37:57-64. https://doi. org/10.1016/0952-3278(89)90187-7

14. Dinkova-Kostova AT, Massiah MA, Bozak RE, Hicks RJ, Talalay P (2001) Potency of Michael reaction acceptors as inducers of enzymes that protect against carcinogenesis depends on their reactivity with sulfhydryl groups. Proc Natl Acad Sci 98(6):3404-3409. https://doi.org/10.1073/ pnas.051632198

15. Sahu PK, Sahu PK, Gupta S, Thavaselvam D, Agarwal D (2012) Synthesis and evaluation of antimicrobial activity of $4 \mathrm{H}$-pyrimido[2,1-b] benzothiazole, pyrazole and benzylidene derivatives of curcumin. Eur J Med Chem 54:366-378. https://doi.org/10.1016/j.ejmech.2012.05.020

16. Din ZU, Lazarin-Bidóia D, Kaplum V, Garcia FP, Nakamura CV, RodriguesFilho E (2016) The structure design of biotransformed unsymmetrical nitro-contained 1,5-diaryl-3-oxo-1,4-pentadienyls for the anti-parasitic activities. J Chem, Arab. https://doi.org/10.1016/j.arabjc.2016.03.005

17. Trott O, Olson AJ (2010) AutoDock Vina: improving the speed and accuracy of docking with a new scoring function, efficient optimization, and multithreading. J Comput Chem 31:455-461. https://doi.org/10.1002/ jcc.21334

18. Dallakyan S, Olson AJ (2015) Small-molecule library screening by docking with pyrx. Chemical Biology: Methods Protocols. Humana Press, New York, pp 243-250. https://doi.org/10.1007/978-1-4939-2269-7

19. Morris GM, Goodsell DS, Halliday RS, Huey R, Hart WE, Belew RK, Olson AJ (1998) Automated docking using a lamarckian genetic algorithm and an empirical binding free energy function. J Comput Chem 19:1639-1662

20. Major C, Pleuvry BJ (1971) Effects of a-methyl-p-tyrosine, $p$-chlorophenylalanine, I- $\beta$-(3,4-dihydroxyphenyl) alanine, 5-hydroxytryptophan and diethyldithiocarbamate on the analgesic activity of morphine and methylamphetamine in the mouse. Br J Pharmacol 42:512-521. https:// doi.org/10.1111/j.1476-5381.1971.tb07137.x

21. Adzu B, Amos S, Kapu S, Gamaniel K (2003) Anti-inflammatory and anti-nociceptive effects of Sphaeranthus senegalensis. J Ethnopharmacol 84(2):169-173. https://doi.org/10.1016/S0378-8741(02)00295-7

22. Bauriedel G, Skowasch D, Schneider M, Andrié R, Jabs A, Lüderitz B (2003) Antiplatelet effects of angiotensin-converting enzyme inhibitors compared with aspirin and clopidogrel: a pilot study with whole-blood aggregometry. Am Heart J 145:343-348. https://doi.org/10.1067/ mhj.2003.22

23. Dey P, Bhakta T (2012) Evaluation of in vitro anticoagulant activity of Molineria recurpata leaf extract. J Nat Prod Plant Resour 2:685-688

24. Gangaraju S, Manjappa B, Subbaiah GK, Kempaiah K, Shinde M, Sannaningaiah D (2015) Anticoagulant and antiplatelet activities of jackfruit (Artocarpus heterophyllus) seed extract. Int J Pharm Pharm Sci 7:187-191. https://doi.org/10.5530/pj.2015.3.5

25. Morris GM, Lim-Wilby M (2008) Molecular docking. Molecular modeling of proteins. Humana Press, New York, pp 365-382

26. Ayyapa B, Kanchi S, Singh P, Sabela MI, Dovey M, Bisetty K (2015) Analytical evaluation of steviol glycosides by capillary electrophoresis supported with molecular docking studies. JICS 12(1):127-136. https://doi. org/10.1007/s13738-014-0465-z
27. Wang R, Lai L, Wang S (2002) Further development and validation of empirical scoring functions for structure-based binding affinity prediction. J Comput Aided Mol Des 16:11-26

28. Gené RM, Segura L, Adzet T, Marin E, Iglesias J (1998) Heterothecainuloides: anti-inflammatory and analgesic effect. J Ethnopharmacol 60(2):157-162

29. Ulugöl A, Özyigit F, Yesilyurt Ö, Dogrul A (2006) The additive antinociceptive interaction between win 55,212-2, a cannabinoid agonist, and ketorolac. Anesth Analg 102:443-447. https://doi.org/10.1213/01. ane.0000194587.94260.1d

30. Arslan R, Bektas N, Ozturk Y (2010) Antinociceptive activity of methanol extract of fruits of Capparis ovata in mice. J Ethnopharmacol 131:28-32. https://doi.org/10.1016/j.jep.2010.05.060

31. Chapman CR, Casey K, Dubner R, Foley K, Gracely R, Reading A (1985) Pain measurement: an overview. Pain 22:1-31. https://doi.org/10.1016/03043959(85)90145-9

32. Matsumoto $H$, Naraba $H$, Ueno A et al (1998) Induction of cycloxygenase-2 causes an enhancement of writhing response in mice. Eur J Pharmacol 352:47-52. https://doi.org/10.1016/S0014-2999(98)00340-9

33. Ballou LR, Botting RM, Goorha S, Zhang J, Vane JR (2000) Nociception in cyclooxygenase isozyme-deficient mice. Proc Natl Acad Sci 97:1027210276. https://doi.org/10.1073/pnas.180319297

34. Bentley GA, Newton SH, Starr J (1981) Evidence for an action of morphine and enkephalins on sensory nerves endings in the mouse peritoneum. $\mathrm{Br}$ J Pharmacol 73:325-332. https://doi.org/10.1111/j.1476-5381.1981.tb104 25.x

35. Bentley GA, Newton SH, Starr J (1983) Studies on the antinociceptive action of a-agonist drugs and their interaction with opioid mechanisms. Br J Pharmacol 73:125-134. https://doi.org/10.1111/j.1476-5381.1983. tb10504.x

36. Chen TF, Tsai HY, Tian-Shang W (1995) Anti-inflammatory and analgesic activities from the roots of Angelica pubescens. Planta Med 61:2-8. https:// doi.org/10.1055/s-2006-957987

37. Pini LA, Vitale G, Ottani A, Sandrini M (1997) Naloxone-reversible antinociception by paracetamol in the rat. J Pharmacol Exp Ther 280:934-940

38. Hosseinzadeh H, Younesi HM (2002) Antinociceptive and anti-inflammatory effects of Crocus sativus stigma and petal extracts in mice. BMC Pharmacol 2:7. https://doi.org/10.1186/1471-2210-2-7

39. Coughlin SR (2000) Thrombin signalling and protease-activated receptors. Nature 407:258-264. https://doi.org/10.1038/35025229

40. Howat JM, Creer MH, Rickard A (2001) Stimulation of protease activated receptors on RT4 cells mediates arachidonic acid release via $\mathrm{Ca}^{2+}$ independent phospholipase $A_{2}$.J Urol 165:2063-2067. https://doi. org/10.1016/S0022-5347(05)66295-7

41. Bukhari SNA, Jantan IB, Jasamai M, Ahmad W, Amjad MWB (2013) Synthesis and biological evaluation of curcumin analogues. J Med Sci 13:501-513. https://doi.org/10.3923/jms.2013.501.513

42. Cao Y-K, Li H-J, Song Z-F, Li Y, Huai Q-Y (2014) Synthesis and biological evaluation of novel curcuminoid derivatives. Molecules 19:16349-16372. https://doi.org/10.3390/molecules191016349

43. Hoult J, Paya M (1996) Pharmacological and biochemical actions of simple coumarins: natural products with therapeutic potential. Vasc Pharmacol 27:713-722. https://doi.org/10.1016/0306-3623(95)02112-4

44. Manikandan P, Sumitra M, Aishwarya S, Manohar BM, Lokanadam B, Puvanakrishnan R (2004) Curcumin modulates free radical quenching in myocardial ischaemia in rats. Int J Biochem Cell Biol 36:1967-1980. https ://doi.org/10.1016/j.biocel.2004.01.030 